NBER WORKING PAPER SERIES

\begin{abstract}
BUBBLES, FOOD PRICES, AND SPECULATION: EVIDENCE FROM THE CFTC'S DAILY LARGE TRADER DATA FILES
\end{abstract}

\author{
Nicole M. Aulerich \\ Scott H. Irwin \\ Philip Garcia \\ Working Paper 19065 \\ http://www.nber.org/papers/w19065
NATIONAL BUREAU OF ECONOMIC RESEARCH
1050 Massachusetts Avenue
Cambridge, MA 02138
May 2013

Nicole M. Aulerich is an Associate at Cornerstone Research. Scott H. Irwin is the Laurence J. Norton Chair of Agricultural Marketing at the University of Illinois at Urbana-Champaign. Philip Garcia is the T.A. Hieronymus Distinguished Chair in Futures Markets at the University of Illinois at UrbanaChampaign. We gratefully acknowledge the helpful discussions and comments provided by Dwight Sanders and Aaron Smith. We also received helpful comments at the 2009 NCCC-134 Conference on Applied Commodity Price Analysis, Forecasting, and Market Risk Management, the 2012 NBER Conference on the Economics of Food Price Volatility and seminars at the Commodity Futures Trading Commission (CFTC) and University of California-Berkeley. Jeff Harris, formerly Chief Economist of the CFTC, and Lin Hoffman of the Economic Research Service of the U.S. Department of Agricultural provided invaluable assistance in obtaining access to the CFTC large trader data files used in this study. This material is based upon work supported by Cooperative Agreement with the Economic Research Service of the U.S. Department of Agriculture under Project No. 58-3000-8-0063. Any opinions, findings, conclusions, or recommendations expressed in this publication are those of the authors and do not necessarily reflect the views of the U.S. Department of Agriculture, the U.S. Commodity Futures Trading Commission, or the National Bureau of Economic Research.

At least one co-author has disclosed a financial relationship of potential relevance for this research. Further information is available online at http://www.nber.org/papers/w19065.ack

NBER working papers are circulated for discussion and comment purposes. They have not been peerreviewed or been subject to the review by the NBER Board of Directors that accompanies official NBER publications.

(C) 2013 by Nicole M. Aulerich, Scott H. Irwin, and Philip Garcia. All rights reserved. Short sections of text, not to exceed two paragraphs, may be quoted without explicit permission provided that full credit, including $\odot$ notice, is given to the source. 
Bubbles, Food Prices, and Speculation: Evidence from the CFTC's Daily Large Trader Data

Files

Nicole M. Aulerich, Scott H. Irwin, and Philip Garcia

NBER Working Paper No. 19065

May 2013

JEL No. D84,G12,G13,G14,Q13,Q41

\begin{abstract}
The "Masters Hypothesis" is the claim that unprecedented buying pressure from new financial index investors created a massive bubble in agricultural futures prices at various times in recent years. This paper analyzes the market impact of financial index investment in agricultural futures markets using non-public data from the Large Trader Reporting System (LTRS) maintained by the U.S. Commodity Futures Trading Commission (CFTC). The LTRS data are superior to publicly-available data because commodity index trader (CIT) positions are available on a daily basis, positions are disaggregated by contract maturity, and positions before 2006 can be reliably estimated. Bivariate Granger causality tests use CIT positions in terms of both the change in aggregate new net flows into index investments and the rolling of existing index positions from one contract to another. The null hypothesis of no impact of aggregate CIT positions on daily returns is rejected in only 3 of the 12 markets. Point estimates of the cumulative impact of a one standard deviation increase in CIT positions on daily returns are negative and very small, averaging only about two basis points. The null hypothesis that CIT positions do not impact daily returns in a data-defined roll period is rejected in 5 of the 12 markets and estimated cumulative impacts are negative in all 12 markets; the opposite of the expected outcome if CIT rolling activity simultaneously pressures nearby prices downward and first deferred prices upward. Overall, the results add to the growing body of literature showing that buying pressure from financial index investment in recent years did not cause massive bubbles in agricultural futures prices.
\end{abstract}

Nicole M. Aulerich

Cornerstone Research

naulerich@cornerstone.com

Scott H. Irwin

Department of Agricultural and Consumer Economics

sirwin@illinois.edu

Philip Garcia

University of Illinois at Urbana-Champaign

Department of Agricultural and Consumer Economics

p-garcia@illinois.edu 


\section{Bubbles, Food Prices, and Speculation: Evidence from the CFTC's Daily Large Trader Data Files}

The nature and cause of recent spikes in commodity prices is the subject of an acrimonious and world-wide debate. Hedge fund manager Michael W. Masters has led the charge that price spikes were driven in large part by a new type of speculator in commodity futures marketsfinancial index investors. ${ }^{1}$ He has testified numerous times before the U.S. Congress and U.S. Commodity Futures Trading Commission (CFTC) (e.g., Masters, 2008, 2009) with variations of the following argument:

"Institutional Investors, with nearly $\$ 30$ trillion in assets under management, have decided en masse to embrace commodities futures as an investable asset class. In the last five years, they have poured hundreds of billions of dollars into the commodities futures markets, a large fraction of which has gone into energy futures. While individually these Investors are trying to do the right thing for their portfolios (and stakeholders), they are unaware that collectively they are having a massive impact on the futures markets that makes the Hunt brothers pale in comparison. In the last $4 \frac{1}{2}$, years assets allocated to commodity index replication trading strategies have grown from $\$ 13$ billion in 2003 to $\$ 317$ billion in July 2008. At the same time, the prices for the 25 commodities that make up these indices have risen by an average of over $200 \%$. Today's commodities futures markets are excessively speculative, and the speculative position limits designed to protect the markets have been raised, or in some cases, eliminated. Congress must act to re-establish hard and fast position limits across all markets." (Masters and White, 2008, p. 1).

In essence, Masters argues that unprecedented buying pressure from index investors created a massive bubble in commodity futures prices, and this bubble was transmitted to spot prices through arbitrage linkages between futures and spot prices. The end result was that commodity prices, crude oil in particular, far exceeded fundamental values. Irwin and Sanders (2012a) use the term "Masters Hypothesis" as a short-hand label for this argument.

\footnotetext{
${ }^{1}$ Commodity index investments are packaged in a variety of forms but share a common goal—provide investors with long-only exposure to returns from an index of commodity prices. Investors may enter directly into over-thecounter (OTC) contracts with swap dealers to gain the desired exposure to returns from a particular index of commodity prices. Some firms also offer investment funds whose returns are tied to a commodity index. Exchange-traded funds (ETFs) and structured notes (ETNs) also have been developed that track commodity indexes. See Engelke and Yuen (2008), Stoll and Whaley (2010), and Irwin and Sanders (2011) for further details on commodity index investments.
} 
Several well-known international organizations (e.g., Robles, Torero, and von Braun, 2009; De Schutter, 2010; Herman, Kelly, and Nash, 2011; UNCTAD, 2011) have been among the most ardent supporters of the Masters Hypothesis, arguing that financial index investors were one of the main drivers of spikes in food commodity prices that have occurred since 2007. Because consumers in less-developed countries devote a relatively high proportion of disposable income to food purchases, a sharp increase in the price of food is harmful to the health and wellbeing of large numbers of people. For example, Robert Zoellick, President of the World Bank Group, stated in February 2011 that, "Global food prices are rising to dangerous levels and threaten tens of millions of poor people around the world. The price hike is already pushing millions of people into poverty, and putting stress on the most vulnerable who spend more than half of their income on food.” (WB, 2011) More directly, the U.S. Senate's Permanent Subcommittee on Investigations (USS/PSI, 2009) concluded that financial index investment in wheat, one of the most important food commodities in the world, constituted "excessive speculation" under the U.S. Commodity Exchange Act. Food price spikes have also been recently linked to riots and political unrest (Bellemare, 2012). In this environment it is not hard to understand why food prices have become such a high-priority issue in public policy debates (e.g., G-20, 2011).

While there has been considerable discussion about the potential conceptual problems of the Masters Hypothesis and contradictory facts (e.g., Irwin, Sanders, and Merrin, 2009; Pirrong, 2010; Wright, 2011; Dwyer, Holloway and Wright, 2012), it should be noted that financial index investment flows may cause market prices to deviate from fundamental values under certain theoretical conditions. Irwin and Sanders (2012a) posit the following conditions: 1) commodity futures market may not be sufficiently liquid to absorb the large order flow of index investors, 2) 
financial index investors are in effect noise traders who make arbitrage risky, and this opens the possibility of index investors 'creating their own space' if their positions are large enough (De Long et al., 1990), and 3) the large order flow of index investors on the long side of the market may be seen (erroneously) as a reflection of valuable private information about commodity price prospects, which has the effect of driving the futures price higher as other traders subsequently revise their own demands upward (Grossman, 1986). Singleton (2011) notes that learning about economic fundamentals with heterogeneous information may induce excessive price volatility, drift in commodity prices, and a tendency towards booms and busts. He argues that under these conditions the flow of financial index investments into commodity markets may harm price discovery and social welfare. ${ }^{2}$

A number of recent studies investigate whether an empirical relationship can be detected between financial index positions and price movements in agricultural futures markets. ${ }^{3,4}$ One line of research uses time-series regression tests, such as Granger causality tests. Gilbert (2009) does not find evidence of a significant time-series relationship between weekly financial index trading and returns in corn, soybeans, and wheat futures markets, but in subsequent work reports

\footnotetext{
${ }^{2}$ Several other recent papers develop theoretical models where financial index investment impacts the price of risk, or risk premiums, in commodity futures markets (Acharya, Lochstoer, and Ramadorai, 2010; Etula, 2010; Brunetti and Reiffen, 2011; Hamilton and Wu, 2011 2012; Cheng, Kirilenko, and Xiong, 2012). Irwin and Sanders (2012b) argue that it is important to contrast the "rational and beneficial" impact of index investment in these theoretical models, which has the net effect of reducing risk premiums and lowering the cost of hedging for traditional physical market participatns, with the "irrational and harmful" impact of index investment under the Masters Hypothesis.

${ }^{3}$ See Fattouh, Kilian, and Mahadeva (2012) for a comprehensive review of studies on the impact of financial index investors, and speculation in general, in the crude oil market.

${ }^{4}$ Some recent studies provide indirect tests of the relationship between financial index positions and agricultural futures prices. For example, Tang and Xiong (2010) conclude that index investing has an impact on commodity prices (agricultural and non-agricultural) based on a trend towards increasing co-movement of futures prices for commodities included in popular investment indexes. In contrast, Buyuksahin and Robe (2011) report that index investment activity is not associated with the increasing correlation between commodity and stock returns. Janzen, Smith, and Carter (2012) find no evidence of increasing co-movement between cotton and crude oil or metal prices after accounting for supply, demand, and inventory shocks specific to cotton. Some recent studies test for the existence of price bubbles in agricultural futures markets (Gilbert, 2009; Phillips and Yu, 2010; Adammer, Bohl, and Stephan, 2011; Gutierrez, 2011), with mixed results.
} 
evidence of a significant relationship with an index of food price changes (Gilbert, 2010) and returns in less liquid agricultural futures markets such as soybean oil, feeder cattle, live cattle and lean hogs (Gilbert and Pfuderer, 2012). Stoll and Whaley (2010) use a variety of tests, including Granger causality tests, and find no evidence that the weekly positions of financial index traders impact prices in 12 agricultural futures markets. Capelle-Blancard and Coulibaly (2011), Sanders and Irwin (2011a, 2011b), and Hamilton and Wu (2012) report similar results for the same 12 agricultural futures markets. Brunetti, Buyuksahin, and Harris (2011) conduct a battery of Granger causality tests and do not find a statistical link between daily index positions and subsequent returns or volatility in the corn futures market.

Motivated by the observation that traditional time-series tests can be criticized for a lack of statistical power due to the large volatility of returns in commodity futures markets (Summers, 1986), a second line of research uses cross-sectional regression tests. Sanders and Irwin (2010) find little evidence that the relative size of weekly financial index positions in 12 agricultural futures markets is correlated to subsequent returns across markets. Irwin and Sanders (2012a) conduct similar cross-sectional tests using quarterly data on financial index positions in 19 agricultural, energy, and metals futures markets and report no evidence of a significant crosssectional relationship with returns or volatility.

A third line of research investigates whether there is a significant relationship between financial index investor trading and the difference, or spread, between futures prices of different contract maturities. Stoll and Whaley (2010), Hamilton and Wu (2012), and Garcia, Irwin, and Smith (2012) conduct various time-series regression tests and do not find a systematic tendency for spreads in agricultural futures markets to increase or decrease over time as financial index positions increase. Irwin et al. (2011) conduct Granger causality tests and do not find a 
significant relationship between index positions and spreads in corn, soybean, and wheat futures markets; however, they do find that spreads increase during the narrow window when existing index positions are rolled from one nearby contract to the next, but the increase is temporary as spreads quickly return to the level prevailing before the roll window. Mou (2010) conducts several tests and concludes that the rolling of positions by index investors leads to a substantial expansion in spreads over time in livestock futures markets and a modest expansion in grain futures markets. Brunetti and Reiffen (2011) estimate a GARCH model and report a negative relationship between index investor positions and spreads in corn, soybeans, and wheat futures markets.

The bulk of the studies reviewed above do not support the Masters Hypothesis in agricultural futures markets. Nonetheless, research to date is subject to important data limitations - as proponents of the Masters Hypothesis have duly noted. ${ }^{5}$ First, public data on financial index positions in agricultural futures markets are only available weekly. This limitation on sample size likely reduces the power of time-series methods to detect index impacts. Weekly observations may also mask impacts that occur over shorter time intervals. Second, public data on index positions are not available prior to 2006. Previous research suggests financial index positions grew most rapidly during 2004-2005 (Sanders, Irwin, and Merrin, 2010; Sanders and Irwin, 2011a; Brunetti and Reiffen, 2011) and excluding this time period may bias tests against finding an impact of index trading. Third, public data on index positions are aggregated across all futures contract maturity months, which does not allow changes in prices and positions to be matched precisely by contract maturity months. This limits

\footnotetext{
${ }^{5}$ For an example, see the letter "Swaps, Spots, and Bubbles" by Sir Richard Branson, Michael Masters, and David Frenk published in the July 29, 2010 issue of the Economist magazine (http://www.economist.com/node/16690679).
} 
the ability to evaluate market impact during the crucial period when index positions are "rolled" from one contract to the next.

The purpose of this paper is to analyze the market impact of financial index investment in agricultural futures markets using non-public data from the Large Trader Reporting System (LTRS) maintained by the U.S. Commodity Futures Trading Commission (CFTC). These data are not subject to the previously-noted limitations since the non-public CFTC data files include financial index investor positions on a daily basis and positions are disaggregated by contract maturity. Furthermore, the data can be used to reliably estimate index trader positions before 2006 in order to capture the period of their most rapid position growth. Daily data from the LTRS are available for the January 2000 through September 2009 sample period. ${ }^{6}$ The 12 agricultural futures markets included in the study are: corn, soybeans, soybean oil, and wheat traded at the Chicago Board of Trade (CBOT); wheat traded at the Kansas City Board of Trade (KCBOT); feeder cattle, lean hogs, and live cattle traded at the Chicago Mercantile Exchange (CME); and cocoa, cotton, coffee, and sugar traded at the Intercontinental Exchange (ICE). This is the first study to use the daily LTRS data files for all 12 agricultural futures markets included in the CFTC's Supplemental Commitments of Traders report. ${ }^{7}$

The empirical analysis considers index investor positions in terms of aggregate new net flows into financial index investment and the rolling of existing index positions from one contract to another. Analysis based on the aggregate new net flows of index investor positions affords the most direct test of the Masters Hypothesis (i.e., a "wave" of financial index investment artificially inflated prices in agricultural futures markets) because aggregate positions represent

\footnotetext{
${ }^{6}$ Data before January 2000 is not considered based on conversations with CFTC staff, who indicated that trader classifications in the LTRS are likely to be less accurate before this date.

${ }^{7}$ Brunetti and Reiffen (2011) use daily LTRS data for the corn, soybean, and wheat futures markets and Brunetti, Buyuksahin, and Harris (2011) use daily LTRS data for the corn futures market.
} 
the new investment decisions of financial index investors. Analysis based on the rolling of existing financial index positions is also important to consider because the size of index position changes in roll periods is substantially larger than the size of position changes in non-roll periods. Stoll and Whaley (2010) argue that roll period tests are most likely to exhibit a price pressure effect due to the size of index position changes during these periods.

Bivariate Granger causality tests are used to investigate lead-lag dynamics between aggregate financial index trader positions and daily futures returns (price changes) or volatility in each agricultural futures market. Volatility tests are less directly related to the Masters Hypothesis but are included because some previous studies find that index trader positions and price volatility are negatively related (Sanders and Irwin, 2011b; Irwin and Sanders, 2012a). Following Capelle-Blancard and Coulibaly (2011) and Sanders and Irwin (2011b), seemingly unrelated regression (SUR) is used to estimate lead-lag dynamics. The SUR approach improves the power of statistical tests by taking into account the contemporaneous correlation of model residuals across markets and allows a test of the overall impact of index investment across markets. In addition, cross-market equality constraints are placed on parameters when appropriate which should further improve the power of statistical tests. The sample for this analysis is limited to January 2004-September 2009 since CIT trading activity is much smaller before this time period. A total of 1,147 daily observations are available over this sample period for each market, which should be more than adequate to efficiently estimate the type of timeseries regression models considered here.

Bivariate Granger causality tests are also used to investigate lead-lag dynamics when the sample is limited to the roll window of index investors. Since index positions are concentrated in nearby contracts (closest to expiration) they must be "rolled" to the next nearest to expiration 
contract before the nearby contract expires. Previous studies typically assume that the roll window is the conventional five-day "Goldman roll." The disaggregated LTRS data allows a more accurate data-dependent roll period to be defined. Bivariate Granger causality tests are conducted in an SUR framework for the nearby and next nearby contracts during the defined roll window for each agricultural futures market. This allows estimation of separate price pressure effects as index investors simultaneously roll positions out of the nearby contract and into the next nearby contract. The large variation in positions of index investors during the roll window should make these statistical tests among the most powerful considered in this study.

\section{CFTC Large Trader Reporting System}

The CFTC Large Trader Reporting System (LTRS) is designed for surveillance purposes to detect and deter futures and options market manipulation (Fenton and Martinaitas, 2005). Positions must be reported to the CFTC on a daily basis if they meet or exceed reporting levels. For example, the current reporting level in the corn futures contract is 250 contracts, or 1.25 million bushels. The LTRS database contains end-of-day reportable positions for long futures, short futures, long delta-adjusted options, and short delta-adjusted options for each trader ID and contract maturity. ${ }^{8,9}$ In recent years about $70 \%$ to $90 \%$ of open interest in commodity futures markets has been reported to the CFTC and included in the LTRS (CFTC, 2012a).

A weekly snapshot of the LTRS data is compiled in aggregate form and released to the general public as the Commitment of Traders report (COT). The COT pools traders into two

\footnotetext{
${ }^{8}$ Delta is the change in option price for a one percent change in the price of the underlying futures contract. Adjusting options positions by delta makes options positions comparable to futures positions in terms of price changes.

${ }^{9}$ The data do not include positions of day traders or scalpers since these participants seldom carry positions overnight.
} 
broad categories (commercial and non-commercial), all contract maturities are aggregated into one open interest figure, and the report is released each Friday with the data as of the end-of-day on the preceding Tuesday (CFTC, 2012b). The COT report covers over 90 U.S. commodity markets and two versions are published: i) the Futures-Only Commitments of Traders report that includes futures market open interest only; and ii) the Futures-and-Options-Combined Commitments of Traders report that includes futures market open interest and delta-weighted options market open interest.

In response to industry concerns regarding financial index positions, the CFTC changed the reporting system in 2007 by creating the Supplemental Commitment of Traders (SCOT) report. This report separates commodity index traders (CITs) from the original commercial and noncommercial COT categories (CFTC, 2006). ${ }^{10}$ CFTC staff engaged in a detailed process to identify index traders in the LTRS for inclusion in the new category. The process included screening all traders with large long positions in commodity futures contracts, analyzing futures positions to determine a pattern consistent with index trading, reviewing line of business forms (Form 40) to obtain more detailed information on their use of the market, and conducting an expansive series of phone and in-person interviews with traders. The CFTC does not distinguish index and non-index positions in this process. So, if a trader is identified as an index trader, then all of their positions are counted as index positions. The first weekly SCOT report was published in January 2007 and provided aggregate futures and delta-adjusted options positions of CITs in 12 agricultural futures markets: CBOT corn, soybeans, soybean oil, and wheat; KCBOT wheat; CME feeder cattle, lean hogs, and live cattle; and ICE cocoa, cotton, coffee, and sugar.

\footnotetext{
${ }^{10}$ In order to be consistent with the terminology used by the CFTC, financial index investors will be referred to as commodity index traders (CITs) in the remainder of the paper.
} 
The CIT category was computed retroactively back through 2006 to provide context for the initial release of the data in 2007.

The CFTC acknowledges that the classification procedure used to create the CIT category was imperfect and that, "Some traders assigned to this category are engaged in other futures activity that could not be disaggregated. As a result, the Index Traders category, which is typically made up of traders with long-only futures positions, will include some short futures positions where traders have multi-dimensional trading activities, the preponderance of which is index trading." (CFTC, 2006) Despite these limitations, Irwin and Sanders (2012a) show that aggregate CIT positions in agricultural futures markets are highly correlated with quarterly benchmark positions available from the CFTC since the end of 2007. This indicates measurement errors associated with aggregate CIT positions are likely rather small and supports the widespread view that CIT data provide valuable information about index trader activity in agricultural futures markets. ${ }^{11}$

As noted, CITs are drawn from the original commercial and noncommercial categories in the LTRS. CITs from the commercial category are traders whose positions predominantly reflect hedging of OTC transactions associated with financial index investors seeking exposure to commodity prices following a standardized commodity index. CITs from the noncommercial category are mostly managed funds, pension funds and other institutional investors also seeking

\footnotetext{
${ }^{11}$ The CFTC created another weekly report based on LRTS positions in 2009 called the Disaggregated Commitments of Traders (DCOT) report. Index trader positions in the DCOT report may be found in three of the four categories created for the report: swap dealers, managed money, and other reportables. While there is a moderately high correlation between swap dealer and CIT positions in agricultural futures markets across the DCOT and SCOT reports, Irwin and Sanders (2012a) show that aggregate CIT positions are more highly correlated with quarterly benchmark positions than those found in the DCOT. Irwin and Sanders (2012a) also show that the correlation between aggregate DCOT swap dealer positions and quarterly benchmark positions in energy and metals futures markets is low due to the active long and short non-index swap trade and consequent internal netting of positions by swap dealers in these markets. This means that aggregate DCOT swap dealer positions in energy and metals futures markets likely mask the true size of index positions, and therefore, represent a poor proxy for total index positions in these markets.
} 
exposure to commodity price movements. Sanders, Irwin and Merrin (2010) show that approximately $85 \%$ of index trader positions in the 12 SCOT markets are in fact drawn from the long commercial category with the other $15 \%$ from the long non-commercial category. This implies that the bulk of index positions in the 12 SCOT markets are initially established in the OTC market and the underlying position is then transmitted to the futures market by swap dealers hedging OTC exposure.

\section{Commodity Index Trader Positions}

Data on the positions of CITs are collected from the LTRS for the same 12 markets included in the weekly SCOT report over January 2000 through September 2009. In contrast to the weekly data on CIT positions made public in the SCOT report, CIT positions collected directly from the LTRS are reported on a daily basis, disaggregated by contract maturity month, and indicate if the position is in futures or options. The CIT classifications are applied retroactively from 2000 through 2005 to approximate CIT positions before the official CFTC index trader classifications that began in 2006. This assumes that traders classified as CITs over 2006-2009 also were CITs in previous period. Discussions with CFTC staff indicate that CIT designations have changed little since the classification scheme was first implemented in 2006, which provides support for its retroactive application. ${ }^{12}$

The growth in CIT positions in commodity futures markets is pronounced during the 2000 to 2009 period. Table 1 provides a breakdown by year of the average daily net long open

\footnotetext{
${ }^{12}$ This assumption does not imply that the number of CIT traders is constant across the sample period. In fact, the number of CIT traders rises over time in parallel with the rise in aggregate CIT positions. For example, the number of CIT traders in corn increases from 7 in 2000 to 31 in 2008. Retroactive application of CIT classifications prior to 2006 could induce two types of misclassification error. First, CITs that traded between 2000 and 2005 but ceased operation sometime before 2006 would be excluded from the CIT category over 2000-2005. Second, traders classified as CITs over 2006-2008 would be incorrectly categorized as CITs over 2000-2006 if they changed their line of business at some point before 2006. Given the stability in CIT classifications over 2006-2008 the likelihood of either type of error is minimal.
} 
interest (long minus short contracts) held by CITs in the 12 markets. Note that CIT futures positions are aggregated across all contract maturities and options positions are excluded. Previous studies (Sanders, Irwin, and Merrin, 2010; Sanders and Irwin, 2011a; Brunetti and Reiffen, 2011) have found that the most rapid period of growth in CIT positions in grain futures markets pre-dated the 2007-08 spike in prices and this general pattern is confirmed in Table 1. There is a small base of positions in 2000-2003, rapid growth during 2004-2005, and then a leveling off or more modest growth during 2006-2009. For example, the net long position of CITs in CBOT wheat increased from an average of 25,702 contracts in 2003 to 134,408 contracts in 2005, over a fivefold increase. The rapid growth in CIT positions is also apparent in CBOT wheat as a percentage of total open interest (long), which increased from $25 \%$ to $55 \%$ over the same time frame. There were some exceptions to this pattern. Growth in CIT positions in feeder cattle, live cattle, coffee, and cocoa was more linear from 2000-2009.

While there is some variation in the pattern across markets, the averages in Table 1 clearly reveal that CITs became large participants in commodity futures markets during a relatively short time frame. By 2009, the lowest CIT percentage of total market open interest was $14 \%$ (cocoa) and the highest was 52\% (cotton). The average across all 12 markets in 2009 was $34 \%$. Concerns about the price impacts of index funds are more understandable in light of the historic magnitude of this structural change in market participation (Irwin and Sanders, 2012b).

Figure 1 provides daily detail on the growth of CIT positions for one of the most actively traded markets, the corn futures market. ${ }^{13}$ Panel A displays the daily net long open interest in terms of number of contracts held by CIT traders for two categories: i) nearby and first deferred

\footnotetext{
${ }^{13}$ The patterns in the corn market are representative of those identified in other markets except where identified in the text. Similar figures for the other commodities are available from the authors.
} 
corn contracts combined, and ii) all other deferred corn contracts combined. Panel B displays the percent of total CIT open interest in all other deferred corn contracts. Separating positions into these two categories highlights any changes in the maturity of futures contracts held by CITs.

Total CIT open interest in corn was at a moderate level, between 25,000 and 50,000 contracts through the end of 2003, and then increased rapidly starting in early 2004, with a peak of more than 425,000 contracts in July 2006. CIT open interest leveled off and then declined thereafter in early 2009 with a subsequent rebound in late 2009. There is an increase in the importance of other deferred contracts in 2007, as reflected by the dark portion of panel A and the line in panel B. For example, about a quarter of CIT positions were held in longer maturity corn futures contracts in 2008. However, the magnitude of the increase in CIT activity for more distant contracts was less pronounced in several markets (soybean oil, feeder cattle, cocoa, coffee, and sugar).

Based on inspection of the data, other characteristics of CIT positions were identified. CIT traders bypass certain cotton, lean hogs, soybeans, and soybean oil contract maturities, presumably due to trading or liquidity costs considerations. These contracts are excluded in the later statistical analysis of price impacts. ${ }^{14}$ It was also determined that CITs do not trade actively in agricultural options markets. The proportion of combined futures and delta-adjusted options positions represented by options has increased modestly over time, but it is unusual for options to make up more than $5 \%$ of the total. As a result only futures positions are used in the later statistical analysis. CIT traders are also interconnected across markets; specifically, this data set

\footnotetext{
${ }^{14}$ CITs generally did not trade in the August and September soybean contracts, August, September, and October soybean oil contract, May lean hog contract, or October cotton contract.
} 
contains 42 unique index traders with 33 trading in 10 or more markets and none trading in less than 5 .

\section{Rolling of Commodity Index Trader Positions}

Since commodity futures contracts have a limited life, CITs develop strategies to transfer (roll) long positions from an expiring contract to a later contract. The S\&P GSCI Index ${ }^{\mathrm{TM}}$ is one of the most widely tracked indexes and the roll process for this index is described as follows:

"The rolling forward of the underlying futures contracts in the excess return index portfolio occurs once each month, on the fifth through ninth business days (the roll period). As explained above, some of the underlying commodity contracts expire in the next month and thus need to be rolled forward. The simplest way to think of the process is as rolling from one basket of nearby futures (the first nearby basket) to a basket of futures contracts that are further from expiration (the second nearby basket). The S\&P $\mathrm{GSCI}^{\mathrm{TM}}$ is calculated as though these rolls occur at the end of each day during the roll period at the daily settlement prices." 15

The implication is that CIT trading ebbs and flows in specific contracts, as positions shift from one maturity to another. The nearby contract carries the majority of the open interest and the deferred contracts constitute the remaining positions.

Figure 2 presents an example of this "ebbing and flowing" for the 2007 calendar year in the March, May, July, September, and December corn futures contracts. Each contract expires roughly in the third week of the expiration month. The top solid black line in panel A represents the net long open interest aggregated across all contracts each business day. Total position size of CITs in corn was about 400,000 contracts at the start of the year, quickly declined to about 350,000 contracts, and then varied little from that level over the remainder of 2007. The "hills" below the total line show the composition of CIT positions on each day and clearly illustrate the

\footnotetext{
${ }^{15}$ This material can be found at the following website: http://www2.goldmansachs.com/services/securities/products/sp-gsci-commodity-index/roll-period.html.
} 
pattern of rolling positions from one contract to the next. Positions build up rapidly during the period when a contract is the nearest-to-maturity (nearby) and decline equally rapidly as the contract approaches expiration and positions are moved the next contract (first deferred) as shown in Panel B. Note that the pattern is somewhat different for the December 2007 "new crop" contract, with positions being held at some level in this contract for almost the entire year. Panel C shows that the changes in the nearby and first deferred series are nearly mirror images. ${ }^{16}$ Changes in the nearby are negative as traders exit this contract and changes in the deferred are positive as traders enter the next contract.

While the pattern of rolling positions from one contract maturity to the next is obvious in in Figure 2, the length of time that the roll period ordinarily encompasses is less obvious. Previous studies (Mou, 2010; Stoll and Whaley, 2010; Irwin et. al, 2011; Hamilton and Wu, 2012) typically assume the roll window is equivalent to the so-called "Goldman roll" period, which as the previous quote indicates, spans the fifth through ninth business day in the calendar month before contract expiration. ${ }^{17}$ The disaggregated LTRS positions allow us to determine if this is a reasonable assumption. As a starting point, Figure 3 displays CIT positions in the December 2004 and December 2008 corn futures contracts for the 25 business days before the Goldman roll period and the 10 business days after. The Goldman roll period coincides with the peak of rolling activity by CITs, but there is also substantial rolling of positions that occurs outside of the Goldman roll. In addition, there is a clear increase in the amount of rolling outside of the Goldman window when comparing 2008 to 2004; a pattern that holds for the other agricultural futures markets and is consistent with numerous accounts in the financial press of

\footnotetext{
${ }^{16}$ The simple correlation between the two series is -0.94 .

${ }^{17}$ The study by Brunetti and Reiffen (2011) is an exception. They consider roll trades to be all position changes of CITs during the period that a contract is in the nearby position.
} 
index traders expanding the time frame in which they roll to mask trades, seek greater liquidity, or capture advantageous spreads (e.g., Meyer and Cui, 2009; Kemp, 2010).

To determine a roll period that encompasses the bulk of CIT rolling activity, four different roll windows are considered: roll window \#1 begins on the $1^{\text {st }}$ business day of the calendar month that falls two months before the contract expiration month and ends on the $10^{\text {th }}$ business day of the month before expiration; roll window $\# 2$ begins on the $10^{\text {th }}$ business day of the calendar month that falls two months before the contract expiration month and ends on the $10^{\text {th }}$ business day of the month before expiration; roll window $\# 3$ begins on the $1^{\text {st }}$ business day of the calendar month before the contract expiration month and ends on the $10^{\text {th }}$ business day of the same month; and roll window $\# 4$ begins on the $5^{\text {th }}$ business day of the calendar month before the contract expiration month and ends on the $9^{\text {th }}$ business day of the same month (Goldman roll window). A schematic of the alternative roll windows is presented in Figure 4.

The percentage of total rolling activity in the four roll windows is presented in Figure 5 for each year over 2004-2009. Total rolling activity is based on the sum of CIT position changes for the two calendar months prior to the expiration month. Note that annual averages for all markets and contracts are shown. Data before 2004 are not presented due to the relatively small amount of rolling activity in these years. The figure shows that roll $\# 1$ and $\# 2$ contain about $90 \%$ of total rolling activity with only a small downward trend over time. Roll \#3 averages about $75 \%$ and declines modestly across the sample period. Roll \#4 (the Goldman roll) contains approximately $65 \%$ of roll activity in 2004 but decreases to only about $50 \%$ in 2009 , which corroborates the trends in Figure 3. In sum, there is a clear danger of missing a substantial part of CIT rolling activity by restricting attention to the Goldman roll window. 


\section{Granger Causality Tests of Aggregate CIT Positions and Returns or Volatility}

Figure 2 highlights the relevance of considering CIT positions in terms of both the change in aggregate new net flows into index investment and the rolling of existing index positions from one contract to another. This follows Stoll and Whaley's (2010) argument that analyzing financial index investment in aggregate and by individual contract maturities is important.

The directional relationship between aggregate CIT positions and agricultural futures prices can be tested two ways. The first and more controversial relationship is the influence of aggregate CIT positions on price movements. This relationship is investigated to determine if the flow of CIT positions systematically precede changes in returns or volatility. This directly tests the Masters Hypothesis, i.e., a "wave" of financial index investment artificially inflated prices and volatility in agricultural futures markets. Aggregate CIT investment flows are used to test these relationships because aggregate positions represent the new investment decisions of index traders. The second, and less debated, relationship is just the reverse - the influence of changes in agricultural futures prices on aggregate index positions. Note that both types of tests focus on the January 2004 through September 2009 period since CIT trading activity is limited before 2004.

\section{Econometric Models}

Granger causality tests are widely used to assess the relationships between two time-series using lead-lag variables. These tests reflect the basic idea that if event $x$ causes event $y$ then event $x$ should precede event $y$ in time. Several recent studies of index trader impacts in commodity futures markets use similar methods and specify commodity futures returns as a function of lagged returns and lagged measures of index trader participation (e.g., Gilbert, 2009; Stoll and 
Whaley, 2010; Brunetti, Buyuksahin, and Harris, 2011; Sanders and Irwin, 2011a,b; Hamilton and $\mathrm{Wu}, 2012$ ). As is well-known, the results of Granger causality tests require careful interpretation. For example, the rejection of the null hypothesis of no Granger causality may not be reflective of a true causal relationship between $x$ and $y$, but rather the omission of variable $z$ that is the true cause of both $x$ and $y$ (Newbold, 1982). Furthermore, the failure to reject the null hypothesis of no Granger causality between $x$ and $y$ is sufficient to imply the absence of "structural causality" only in the case of a linear system (Hoover, 2001, p.155). Despite these and other related issues, Hamilton (1994) argues that,

“...Granger causality tests can be a useful tool for testing hypotheses that can be framed as statements about the predictability of a particular series. On the other hand, one may be skeptical about their utility as a general diagnostic for establishing the direction of causation between two arbitrary series. For this reason, its best to describe these as tests of whether $y$ helps forecast $x$ rather than tests of whether $y$ causes $x$. The tests may have implications for the latter question, but only in conjunction with other assumptions." (p. 308)

Since agricultural futures prices and CIT positions are not two arbitrary series but instead are posited to have a direct relationship under the Masters Hypothesis, Granger causality tests should be useful in detecting a relationship between the two series if one exists.

Equations (1) and (2) display the specification for Granger causality tests between returns or volatility, respectively, and aggregate CIT positions,

$$
\begin{aligned}
& R_{t, k}=\alpha_{k}+\sum_{i=1}^{m} \gamma_{i, k} R_{t-i, k}+\sum_{j=1}^{n} \beta_{j, k} X_{t-j, k}+\varepsilon_{t, k} \\
& V_{t, k}=\alpha_{k}+\sum_{i=1}^{m} \gamma_{i, k} V_{t-i, k}+\sum_{j=1}^{n} \beta_{j, k} X_{t-j, k}+M_{t, k}+v_{t, k}
\end{aligned}
$$

where $R_{t, k}$ is the return $\left[R_{t, k}=\left(\ln P_{t, k}-\ln P_{t-1, k}\right)^{*} 100\right]$ on day $t$ in market $k, X_{t, k}$ is the change in the aggregate net long CIT position (long minus short contracts), $V_{t, k}$ is implied volatility, and $M_{t, k}$ 
is a set of monthly dummy variables to allow for changing seasonal volatility (these dummy variables are only used if significant). The null hypothesis of no CIT impact is that the slope coefficients, $\beta_{j}$, in (1) or (2) equal zero. An alternative consistent with a bubble-type impact and the "Masters Hypothesis" is that the $\beta_{j}>0$, such that an increase in CIT positions portends relatively large subsequent returns or volatility. ${ }^{18}$

The nearby series for most futures markets is computed by rolling from the nearby contract to the first deferred contract on the last day of the month prior to the expiration month of the nearby contract, which is the convention in numerous previous studies. For instance, in February the nearest contract for corn is March. On the last business day in February the price series is rolled to May, the next nearest contract. Price and position changes are not calculated across contracts, so changes on a switching date correspond to the contract entering the series. Due to the nature of their contract expiration rules, cocoa, coffee, cotton, and sugar are rolled on the day following the 15 th day of the month prior to the delivery month. Implied volatility is a widely accepted method of calculating forward-looking volatility (e.g., Hull, 2000, p. 255). It is obtained from barchart.com and computed as the mean implied volatility of the two nearest-themoney calls and the two nearest-the-money puts for nearby contracts using the Black options pricing model.

A total of 1,147 daily observations over January 2004-September 2009 are available for each of the 12 agricultural futures markets, which should be more than adequate for efficiently estimating the type of time-series regression models considered. For all variables, an augmented

\footnotetext{
${ }^{18}$ This specification could be extended to include the positions of other types of traders in agricultural futures markets, e.g., non-commercial and commercial market participants. Such a multivariate specification could potentially improve the power of the Granger causality tests since the tests would be conditioned on the dynamic interaction of multiple types of traders rather than index traders alone. Two previous studies conduct this type of multivariate analysis (Stoll and Whaley, 2010; Brunetti, Buyuksahin, and Harris, 2011) and do not find that conditioning on other traders' positions substantially alters Granger causality test results.
} 
Dickey-Fuller test is used to test for stationarity. In every case, the test including a constant and trend rejects the null hypothesis of non-stationarity. ${ }^{19}$ The lag structure, $(m, n)$, for each market is determined by a search procedure over $m=5$ and $n=5$ and choosing the model that minimizes the Schwartz criteria to avoid over-parmeterization (Enders, 1995, p. 88).

Following Capelle-Blancard and Coulibaly (2011) and Sanders and Irwin (2011b), we increase the power of causality tests by modeling the $K$ markets as a system. Since the error term in (1) or (2) is contemporaneously correlated across markets, the power of causality tests can be increased by applying Zellner's Seemingly Unrelated Regression (SUR) framework (see Harvey, 1991, p. 69). Efficiency gains over OLS estimates increase with the contemporaneous correlation between errors and with the number of equations. Except for the two studies noted above, previous research on the lead-lag relationship between CIT positions and commodity futures returns conducts tests on a market-by-market basis. This may result in a loss of statistical power because information on the correlation of the error term across markets is ignored.

To further increase statistical power, coefficients are restricted across market equations when appropriate (see Harvey, 1991, p. 69). The strategy for selecting the restricted SUR model follows the sequential testing procedure outlined by Harvey (1991, p. 186) where the most general model is first estimated (no cross-market parameter restrictions). Then, using a Wald test, the hypothesis of equal parameter estimates is tested across markets. When the null of equal parameter estimates is not rejected, then the restriction is placed on the model. Specifically, all $K$ models are first estimated as an SUR system using the lag structure chosen with the OLS search procedure. Then, for each estimated parameter the null hypothesis that the cross-equation parameters are equivalent is tested (e.g., $\gamma_{1,1}=\gamma_{1,2}=\ldots=\gamma_{1, K}$ ). If the null hypothesis is not rejected

\footnotetext{
${ }^{19}$ Since non-stationarity tests have low power, Enders (1995) argues that rejection of the null with a constant and trend provides strong evidence that a series is stationary. Detailed results are available from the authors.
} 
the parameter restriction is imposed resulting in a pooled estimate or single parameter across equations (e.g., $\gamma_{1}$.). By pooling parameters - when we fail to reject that they are equivalentthe number of parameter estimates is decreased and efficiency is further enhanced.

Bivariate causality in a single market, $k$, is tested under the null hypothesis in (1) or (2) that CIT positions cannot be used to predict (do not lead) market returns: $H_{0}: \beta_{j, k}=0$ for all $j$. A rejection of this null hypothesis, using an $F$-test of the stated restriction, provides direct evidence that CIT positions are indeed useful for forecasting returns or volatility in that market. In order to gauge the aggregate impact of CIT positions in a given market, the null hypothesis that $\sum_{j=1}^{n} \beta_{j, k}=0$ in each $k$ market reveals the cumulative directional impact of traders positions on returns or volatility. Clearly, in the event that the lag structure is $n=1$ then the test of null hypothesis that $\sum_{j=1}^{n} \beta_{j, k}=0$ is equivalent to a simple test on the parameter restriction that $\beta_{1, k}=0$. Finally, the SUR estimation allows for the testing of system-wide causality, $H_{0}: \beta_{j, k}=0$ for all $j$ and $k$, and for the systematic impact across all 12 agricultural futures markets, $\sum_{k=1}^{12} \sum_{j=1}^{n} \beta_{j, k}=0$. This is an important improvement over a strictly market-by-market OLS approach to causality testing because it allows for broader statements about systematic impacts. ${ }^{20}$

Grosche (2012) and Gilbert and Pfuderer (2012) argue that hypothesis tests such as those outlined above should be viewed through the lens of informational efficiency. Specifically, the Efficient Markets Hypothesis (EMH) implies that prices reflect all available public information, and therefore, it is impossible at time $t$ to forecast the price for any future period $t+k$ based on the

\footnotetext{
${ }^{20}$ For comparison purposes we estimated equations (1) and (2) using ordinary least squares (OLS) market-bymarket. In addition, we estimated the reverse causality versions of equations (1) and (2) using OLS market-bymarket. The OLS estimation results, which are qualitatively similar to the SUR results presented in following sections, are reported in the Appendix.
} 
public information set available at $t$ (Fama, 1970). Consequently, Grosche and Gilbert and Pfuderer indicate that it would be surprising to find that past CIT positions predict current returns in relatively efficient agricultural futures markets. A problem with applying this argument to the present study is that the disaggregated daily CIT positions from the LTRS are never released to the public. While it is true that an aggregate snapshot of LTRS positions is released in the CFTC's weekly COT report, the data for this report are compiled on Tuesday but not released to the public until the following Friday. Since the CIT positions from the LTRS, in either disaggregated or aggregated form, are not in the public domain on a given date, the informational efficiency issue raised by Grosche and Gilbert and Pfuderer is not applicable to the Granger causality regressions estimated in this study.

\section{Aggregate CIT Positions Do Not Cause Returns or Volatility}

Tests of the null hypothesis that aggregate CIT positions do not impact daily returns are reported in Table 2. The second column presents the minimum BIC lag structure $(m, n)$ and it is $(1,1)$ for all commodities except live cattle and lean hogs. The cross-market restriction of equal intercept terms is imposed, while the remaining parameters are allowed to vary across markets. The third column presents the p-value for the test of the null hypothesis that aggregate CIT positions do not lead returns in each individual market, $\beta_{j, k}=0 \forall j$. The null is rejected in 3 of the 12 markets (feeder cattle, lean hogs, and KCBOT wheat), however, in each of these cases the fourth column shows that the cumulative estimated impact $\left(\sum_{j=1}^{n} \beta_{j}\right)$ is negative. The fifth column reports the p-value associated with a test of the null hypothesis that the cumulative impact is zero for each market. When $n=1$ the cumulative test is redundant; this is the case for all 
commodities in Table 2 except for live cattle. In order to assess the economic magnitude of estimated impacts, column six displays the one standard deviation cumulative impact of aggregate CIT positions on returns. In all cases point estimates of the cumulative impact of a one standard deviation change in CIT positions on daily returns is very small, ranging from only $-0.127 \%$ to $0.034 \%$ and averaging $-0.022 \%{ }^{21}$ In other words, a one-standard deviation increase in the aggregate net long position of CITs leads to a subsequent decline in daily futures prices averaging only about two basis points.

The system-wide tests at the bottom of Table 2 show that the null of no CIT impact across all 12 markets is rejected despite the fact that significant impacts are found in only 3 of the 12 individual market tests. The estimated cumulative system impact is negative, which again indicates that when CITs increase their aggregate position level agricultural futures prices subsequently decline. One interpretation of this result is that the large order flow of CITs temporarily pushes price above fundamental value, and since the impact is temporary, current CIT position changes and subsequent returns are negatively correlated. This is the classic problem of illiquidity arising from the asynchronous arrival of traders to the marketplace (Grossman and Miller, 1988). This interpretation is also consistent with the results of a recent study by Henderson, Pearson, and Wang (2012), who find significant order flow impacts associated with the futures hedging trades of commodity-linked notes issuers.

An alternative interpretation of the negative system impact is that CIT trading results in a re-pricing of risk in commodity futures markets. For example, Hamilton and $\mathrm{Wu}$ (2012) develop a theoretical model where the long "investment hedging" demand of index investors is met by short "arbitrageurs" in the futures market. The risk-averse arbitrageurs are compensated for

\footnotetext{
${ }^{21}$ The average one standard deviation daily change in aggregate net long CIT positions for the 12 markets is about 1,000 contracts, with corn $(2,760)$ the largest and feeder cattle (109) the smallest.
} 
taking on this risk by an embedded upward bias in futures prices before expiration. In this framework, the initiation of long positions by CITs drives the current futures price above the expected price at expiration. Futures prices then subsequently decline as expiration approaches to reward short arbitrageurs for providing risk transfer services to CITs-exactly the opposite direction of the bias predicted by the traditional Keynesian theory of risk premiums in commodity futures markets (e.g., Irwin and Sanders, 2012c). ${ }^{22}$ In the context of agricultural futures markets, this implies that physical market participants, such as farmers and grain merchants, are paid a positive risk premium for taking what have traditionally been regarded as short hedging positions.

Regardless which one of the previous interpretations is ultimately correct, it is important to emphasize that the size of the estimated system impact, only about two basis points, is too small to be consistent with the Masters Hypothesis. Overall, the aggregate return test results are inconsistent with the claim that buying pressure from financial index investment in recent years caused a massive bubble in agricultural futures prices. In this sense the results are similar to the bulk of previous research on the issue.

Tests of the null hypothesis that CITs do not impact implied volatility are reported in Table 3. The lag structure is $(5,1)$ or $(4,1)$ for all markets. The single lag of CIT positions is restricted to be equal across equations, and therefore, all p-values are equivalent. The null hypothesis is not rejected in any of the 12 markets and the estimated size of the cumulative impact is very small; on average, the estimated cumulative impact of a one standard deviation change in CIT positions on implied volatility is a miniscule $-0.003 \%$, less than one basis point.

\footnotetext{
${ }^{22}$ Hamilton and $\mathrm{Wu}$ (2012) do not find any significant evidence of a CIT risk premium impact in the same 12 agricultural futures markets studied here. However, their empirical tests are based on the weekly data available publically from the CFTC. The small impact detected in our study may be due to the use of higher frequency daily data.
} 
Not surprisingly, the system-wide test is also insignificant. While the direction of the volatility impact estimated here is consistent with the evidence in previous studies (Brunetti, Buyuksahin, and Harris, 2011; Sanders and Irwin, 2011b; Irwin and Sanders, 2012a), the magnitude is much smaller. It is not clear whether this is due to differences in sample periods, data sources for CIT positions, or frequency of observations (e.g., daily vs. weekly).

We conducted two robustness checks for the tests reported in this section. First, we conducted a parallel set of Granger causality tests using the percentage change in aggregate net long CIT positions. Results are qualitatively similar to those reported in the text using changes in the number of contracts. We also tested an alternative measure of volatility—Parkinson's (1980) high-low estimator. Again, similar results were found to those based on implied volatility. These additional results are available from the authors on request.

\section{Returns or Volatility Do Not Cause Aggregate CIT Positions}

The previous section examined the influence of aggregate index positions on prices and volatility; this section investigates the reverse relationship — the influence of returns or volatility on aggregate index positions. The same SUR framework is used to estimate the reversecausality regressions, except now the dependent variable in equations (1) and (2) is the change in CIT positions. Table 4 presents the reverse causality regression results for returns and CIT positions. The minimum BIC lag structure $(m, n)$ ranges from 1 to 5 for $m$ and from 1 to 4 for $n$. The null hypothesis that returns do not lead positions is rejected at the $5 \%$ level for 8 of the 12 markets. All cumulative impacts are positive. For example, a one standard deviation increase in returns of $1.5 \%$ in lean hogs increases CIT positions by approximately 36 contracts, a relatively 
small increase in positions. The system-wide tests at the bottom of the table indicate a highly significant impact of returns across all 12 markets, but the magnitude is still relatively small.

Table 5 presents the reverse causality regression results for implied volatility and CIT positions. The null hypothesis that implied volatility does not impact changes in CIT net positions is rejected in 5 of the 12 markets at the 5\% level and the cumulative impact in each of these 5 markets is negative. For example in cocoa, a one standard deviation increase in implied volatility of $8.2 \%$ leads to a 19 contract decrease in CIT positions. The overall system coefficient is also negative and significant, but again the magnitude of the impact is very small.

In sum, index positions have a small but positive relationship to past price movements indicating a trend-following component to net financial index investment flows into agricultural futures markets. Furthermore, index positions have a weak but inverse relationship to price volatility. The combined findings on returns and volatility show that CITs have a tendency to increase aggregate positions when they perceive a clear upward trend in prices as compared to choppy market conditions. This provides the first evidence that index investors are not solely passive buy-and-hold investors, but are to some degree price-sensitive trend-followers, similar to more traditional speculators in agricultural futures markets (Bryant, Bessler, and Haigh, 2006; Sanders, Irwin, and Merrin, 2009). ${ }^{23}$ The results challenge the view that index investors should not be classified as speculators due to the "pure" diversification motive underlying their trading (Stoll and Whaley, 2010).

\footnotetext{
${ }^{23}$ A possible confounding factor is the behavior of swap dealers who manage the bulk of CIT positions in agricultural futures markets. It is possible that index investors have "pure" diversification motives but swap dealers manage the hedging positions in futures markets in an active manner. In other words, swap dealers may not mechanically hedge swap positions in futures but instead engage in a "selective hedging" strategy in an effort to enhance the total profits of their book of swap business. If this is the case, then the trend-following component detected in CIT positions should be attributed to swap dealer behavior not the underlying index investors.
} 


\section{Granger Causality Tests of Roll Period CIT Positions and Returns or Volatility}

In the previous section, aggregate new net flows of index investment into agricultural futures markets were not found to impact subsequent daily returns or volatility in agricultural futures markets. This is not entirely surprising since the average standard deviation of daily changes in aggregate CIT positions across the 12 markets is only approximately 1,000 contracts. In contrast, the vast majority of existing index positions must be rolled from one futures contract maturity to another before expiration. This is clearly illustrated in Figure 2 for the corn market. Recall for 2007, the aggregate position is quite stable around 350,000 contracts for most of the year (top black line), but this entire position must be rolled every few months from one contract to another (lower lines). As Stoll and Whaley (2010) point out, if index investment does impact market prices it may be more likely to do so in the roll period because the size of index position changes during the roll period dwarfs the size of changes in non-roll periods.

\section{Econometric Models}

Similar to the analysis of aggregate index investment impacts, bivariate Granger causality regression is used to analyze lead/lag dynamics between CIT positions and returns during roll periods. Because the rolling of positions is essentially the simultaneous selling of positions in the nearby contract and buying of positions in the first deferred contract (see the bottom panel in Figure 2), regressions are specified separately for each contract series in a given market as follows,

$$
N R_{t}=\alpha+\sum_{i=1}^{m} \gamma_{i} N R_{t-i}+\sum_{j=1}^{n} \beta_{j} N X_{t-j}+\varepsilon_{t}
$$




$$
D R_{t}=\alpha+\sum_{i=1}^{m} \gamma_{i} D R_{t-i}+\sum_{j=1}^{n} \beta_{j} D X_{t-j}+\varepsilon_{t}
$$

where $N R_{t}$ is the return for day $t$ in the nearby contract during the roll period, $N X_{t-j}$ is the change in CIT positions for day $t-j$ in the nearby contract during the roll period, $D R_{t}$ is the return for day $t$ in the first deferred contract during the roll period, and $D X_{t-j}$ is the change in CIT positions for day $t-j$ in the first deferred contract during the roll period. This specification allows estimation of separate price pressure effects as index investors simultaneously roll positions out of the nearby contract and into the first deferred contract. Most previous studies have restricted the estimates of price pressure effects to be the same for the two contract series (Mou, 2010; Stoll and Whaley, 2010; Brunetti and Reiffen, 2011; Garcia, Irwin, and Smith, 2011; Irwin et al., 2011). In contrast, we test whether this restriction is consistent with the data before imposing it in the estimation. Equations (3) and (4) are estimated as an SUR system using the same procedure described earlier except that instead of a system across markets, the system is estimated for the two regressions for each individual market. The large variation in CIT positions during the roll window should make these statistical tests among the most powerful considered in this study.

Our prior analysis shows that a substantial part of CIT rolling activity may be omitted if attention is restricted to the conventional Goldman roll window. Instead, we define the roll window to begin on the $10^{\text {th }}$ business day of the calendar month that falls two months before the contract expiration month and ends on the $10^{\text {th }}$ business day of the month before expiration (Figure 4, roll period \#2). For example, the March 2008 contract maturity roll period spans midJanuary 2008 to mid-February 2008. This window consistently includes approximately $90 \%$ CIT rolling activity in agricultural futures markets. Note that non-roll days are not included in the 
analysis; although, lags that occur prior to the defined roll period may be included as explanatory variables. However, no observations are lagged across roll period windows. ${ }^{24}$

Interpretation of the $\beta$ coefficients in equations (3) and (4) must be done with care.

Specifically, if CIT rolling activity impacts returns in the nearby contract as CITs "roll out" this would be in the form of decreasing returns due to selling pressure (negative position changes). Conversely, the impact in the first deferred contract would be in the form of increasing returns due to buying pressure (positive position changes). In both situations the relationship between CIT position changes and returns is positive, and therefore, implies positive $\beta$ coefficients. Note that the $\beta$ coefficients can also be used to infer index investment impact on the spread between the nearby and first deferred contract. Assuming the nearby price is lower than the deferred price (i.e., the market is normally in a state of contango), then the spread between the two contracts increases if nearby prices decrease and/or first deferred prices increase during the roll window.

In addition to testing returns, SUR systems are also specified to estimate lead/lag dynamics between CIT positions and implied volatility in a given market,

$$
\begin{aligned}
& N V_{t}=\alpha+\sum_{i=1}^{m} \gamma_{i} N V_{t-i}+\sum_{j=1}^{n} \beta_{j} N X_{t-j}+\varepsilon_{t} \\
& D V_{t}=\alpha+\sum_{i=1}^{m} \gamma_{i} D V_{t-i}+\sum_{j=1}^{n} \beta_{j} D X_{t-j}+\varepsilon_{t} .
\end{aligned}
$$

where $N V_{t}$, is implied volatility on day $t$ for the nearby contract, $D V_{t}$ is implied volatility on day $t$ for the first deferred futures contract, and other variables are as defined above.

\footnotetext{
${ }^{24}$ To clarify, the variables are lagged prior to removing the days outside the roll window. For example, returns on day $t$ may be the independent variable and lag of positions on day $t-1$ may be the explanatory variable. If $t$ is the first day of the roll period, then $t-1$ positions would not be in the roll period. In this estimation $t-1$ positions are still used in the estimation as the roll period definition is only applied to the independent variable $t$.
} 


\section{Roll Period CIT Positions Do Not Cause Returns or Volatility}

Tests of the null hypothesis that CIT position changes do not impact returns during roll windows are reported in Table 6 . The minimum BIC lag structure $(m, n)$ ranges from 1 to 2 for $m$ and 1 to 5 for $n$. The hypothesis that coefficients on lagged CIT position changes are the same for the nearby and first deferred contract regressions was rejected only for the cotton market. Therefore, the restriction that the coefficients are the same was imposed in the estimation for the other 11 markets. Note that $\mathrm{p}$-values and cumulative coefficient estimates are based on system tests for the two regression equations for each market. Specifically, the p-values reported in the third column apply to the null hypothesis that CIT position changes during the roll window do not impact returns in both the nearby and first deferred regressions. This joint null hypothesis is rejected at the $5 \%$ level in 5 of the 12 markets. Estimated cumulative impacts are negative in all 12 markets, the opposite of the expected outcome if CIT rolling activity pressures nearby prices downward and first deferred prices upward. For example, a one standard deviation decrease in nearby CIT positions in cotton increases nearby returns by $0.10 \%$; likewise, a simultaneous one standard deviation increase in deferred CIT positions in cotton decreases deferred returns by $-0.10 \%$. This in effect narrows the spread between the nearby and first deferred contract by $0.20 \%$, or almost twenty basis points, assuming the nearby price is lower than the deferred price (i.e., the market is normally in a state of contango). Significant cumulative impacts are found in five markets: cocoa, cotton, lean hogs, live cattle, and KCBOT wheat. It is interesting to note that these five markets represent either non-storable commodities (lean hogs, live cattle) or relatively low volume agricultural futures markets (cocoa, cotton, KCBOT wheat). These markets historically have had limited participation by commercial hedgers and/or poor liquidity, 
and therefore, would be most likely to benefit by the additional trading activity and liquidity associated with index investors.

The results reported in Table 6 imply that CIT positions contribute, on average, to narrowing spreads between agricultural futures contracts and contrast with the findings in previous studies that CIT positions either have no impact on spreads (Stoll and Whaley, 2010; Garcia, Irwin, and Smith, 2011; Irwin et al., 2011; Hamilton and Wu, 2012), or increase spreads (Mou, 2011). The one other study that reports a negative relationship is Brunetti and Reiffen (2011), which is, interestingly, the only other study of spreads that used LTRS data on CIT positions. Since the LTRS data contains daily CIT positions by maturity month, this should presumably allow more accurate estimation of spread impacts than weekly tests based on aggregate CIT positions or tests based on alternative position estimation approaches. ${ }^{25}$ Brunetti and Reiffen (2011) argue that the narrowing of spreads associated with increasing CIT positions can be explained by the impact index investment has on risk premiums. Specifically, index investment increases the supply of market risk-bearing capacity and lowers the overall cost of hedging. Since CIT positions are concentrated in near maturity contracts, spreads narrow due to the larger impact on the risk premium for near contracts relative to deferred contracts. Another possibility is a "sunshine trading effect" (Admati and Pfleiderer, 1991), where the credible preannouncement that a trade is not based on private information changes the nature of informational asymmetries in the market. This preannouncement can have the effect of coordinating the supply and demand of liquidity in the market and reducing the trading costs of those who preannounce such trades. While our works shows that the rolling activity of CITs occurs over a wider window than the narrow five-day Goldman roll, it is

\footnotetext{
${ }^{25}$ Mou (2010) uses a yearly estimate of CIT investment divided by average market value.
} 
nonetheless true that that the majority of CIT rolling occurs in this narrow window using preannounced and mechanical rules for rolling positions. Hence, it is plausible that the net effect of the rolling of CIT positions is to narrow spreads. This is also consistent with the findings of a recent study by Bessembinder et al. (2012), who report that roll trades by exchange-traded funds (ETFs) in the crude oil futures market are associated with narrower bid-ask spreads, greater market depth, and a larger number of traders providing liquidity services on roll versus non-roll dates.

Tests of the null hypothesis that CIT position changes do not impact implied volatility during roll windows are reported in Table 7. If CITs impact realized volatility during the roll period, then both the nearby and deferred contracts are expected to exhibit increases in volatility as index traders rolling causes rapid fluctuations in prices due to their trading activity. ${ }^{26}$ Note that under this scenario $\beta$ coefficients in equation (5) for the nearby contract would be negative and $\beta$ coefficients in equation (6) for the deferred contract would be positive. The hypothesis that coefficients on lagged CIT position changes are the same for the nearby and first deferred contract regressions was rejected only for the cocoa market. Therefore, the restriction that the coefficients are the same was imposed in the estimation for the other 11 markets.

The results in Table 7 indicate the null hypothesis of no impact on implied volatility is rejected for only 2 of the 12 markets (cocoa and feeder cattle). Cumulative impacts are positive for 9 of the 12 markets. However, one must examine the one standard deviation impact to disentangle the signs for the nearby and deferred contracts. Here we see that nearby coefficients generally are all positive, implying that CITs exiting the nearby contract tend to reduce implied volatility; whereas just the opposite result is found for the first deferred contract. For both the

\footnotetext{
${ }^{26}$ This is slightly different than examining volatility when aggregate CIT positions are the explanatory variable. In this short roll period, the transfer of open interest from the nearby to first deferred would be expected to increase volatility in both contracts.
} 
nearby and first deferred contracts the magnitude of the impact on implied volatility is very small. As an example, a one standard deviation decrease in nearby CIT positions in soybeans increases nearby and first deferred implied volatility just $0.01 \%$, or one basis point. The only market with a notable impact is cocoa, where the one standard deviation impact in both series is about $0.30 \%$. Overall, the evidence suggests that the impact of CIT position changes on implied volatility during roll periods is negligible.

We conducted several robustness checks for the roll period tests reported in this section. The first is motivated by the argument that CITs do not make decisions during the roll period based on expectations of future returns, which would make positions and prices exogenous. For this reason, equations (3) and (4) were also estimated without lagging CIT positions, i.e., $j=0$ instead of $j=1$. The results were qualitatively similar to the results using lagged CIT positions. As before, the second check uses the percentage change in aggregate net long CIT positions. Results are qualitatively similar to those reported in the text using changes in the number of contracts. The third check is to use Parkinson's (1980) high-low estimator in volatility tests. We again found similar results to those based on implied volatility. All of these additional results are available from the authors on request.

As a final robustness check we computed the simple contemporaneous correlation between CIT position changes, returns, and implied volatility. We computed these correlations for both the data-defined roll period (\#2) and the conventional Goldman roll (\#4) in order to check the sensitivity of the findings to alternative definitions of the roll period. One can view this test as the most favorable with regard to detecting market impact of CITs because it is based solely on contemporaneous observations and it is the period of largest changes in CIT positions. Table 8 presents the estimated contemporaneous correlations between changes in CIT positions 
and returns or volatility. Panel A shows that, with just a few exceptions, the correlations are very small; only 9 out of the 48 are larger than 0.10 in absolute value. Just 3 of the 48 correlations are statistically significant. The average correlation is only -0.01 and 0.02 . This provides even less evidence of CIT impact on returns during roll periods than the Granger causality tests. In contrast, panel B shows widespread evidence of contemporaneous correlation between CIT position changes and implied volatility -32 of the 48 correlations are statistically significant. A clear tendency emerges of a positive correlation for nearby implied volatility and negative for first deferred implied volatility. Interestingly, this pattern indicates volatility for both the nearby and deferred futures contracts declines during roll periods, i.e., volatility declines as CITs exit the nearby contract and enter the first deferred contract. The size of the correlations is also striking, with an average of 0.20 for nearby and -0.31 first deferred across all 12 markets during the Goldman roll window.

\section{Summary and Conclusions}

The nature and cause of recent spikes in commodity prices is the subject of an acrimonious and world-wide debate. Hedge fund manager Michael W. Masters has led the charge that unprecedented buying pressure from new financial index investors created a massive bubble in commodity futures prices at various times in recent years. Irwin and Sanders (2012a) use the term "Masters Hypothesis" as a short-hand label for this argument. Several well-known international organizations have been among the most ardent supporters of the Masters Hypothesis (see Robles, Torero, and von Braun, 2009; De Schutter, 2010; Herman, Kelly, and Nash, 2011; UNCTAD, 2011), arguing that financial index investors were one of the main drivers of spikes in food commodity prices that have occurred since 2007. Because consumers in 
less-developed countries devote a relatively high proportion of disposable income to food purchases, sharp increases in the price of food can be quite harmful to the health and well-being of large numbers of people.

A number of recent studies investigate whether an empirical relationship can be detected between financial index positions and subsequent price movements in agricultural futures markets (e.g., Gilbert, 20092010 2012; Stoll and Whaley, 2010; Capelle-Blancard and Coulibaly, 2011; Sanders and Irwin, 2011a 2011b; Hamilton and Wu, 2012). While most of these studies do not support the Masters Hypothesis, the data used in nearly all of these studies are subject to important limitations. Specifically, public data on financial index positions in agricultural futures markets are only available on a weekly basis, in aggregate form, and not before 2006 when growth in index positions was most rapid.

The purpose of this paper is to analyze the market impact of financial index investment in 12 agricultural futures markets using non-public data from the Large Trader Reporting System (LTRS) maintained by the U.S. Commodity Futures Trading Commission (CFTC). The LTRS data are superior to publicly-available data because commodity index trader (CIT) positions are available on a daily basis, positions are disaggregated by contract maturity, and positions before 2006 can be reliably estimated. Bivariate Granger causality tests use CIT positions in terms of both the change in aggregate new net flows into index investment and the rolling of existing index positions from one contract to another. Analysis based on the aggregate new net flows of index investor positions affords the most direct test of the Masters Hypothesis because aggregate positions represent the new investment decisions of financial index investors. Analysis based on the rolling of existing financial index positions is also important to consider because the size of index position changes in roll periods is substantially larger than the size of position changes in 
non-roll periods. Stoll and Whaley (2010) argue that roll period tests are most likely to exhibit a price pressure effect due to the size of index position changes during these periods. Previous studies typically assume that the roll window is the conventional five-day "Goldman roll." The disaggregated LTRS data allows us to define a more accurate data-dependent roll period.

A seemingly unrelated regression (SUR) system framework is used to estimate lead-lag dynamics in order to increase the power of causality tests. A total of 1,147 daily observations over January 2004-September 2009 are available from the LTRS for each of the 12 agricultural futures markets. The null hypothesis of no impact of aggregate CIT positions on daily returns is rejected in only 3 of the 12 markets. Point estimates of the cumulative impact of a one standard deviation increase in CIT positions on daily return are negative and very small, with the negative impact averaging only about two basis points. Parallel tests generally fail to reject the null hypothesis that aggregate CIT positions impact implied volatility. Reverse causality tests show that aggregate CIT positions have a small positive relationship to past daily returns and a weak negative relationship to implied volatility. The combined findings on returns and volatility show that CITs have a tendency to increase aggregate positions when they perceive a clear upward trend in prices as compared to choppy market conditions. This provides the first evidence that index investors are not solely passive buy-and-hold investors, but are to some degree pricesensitive trend-followers, similar to more traditional speculators in agricultural futures markets (Bryant, Bessler, and Haigh, 2006; Sanders, Irwin, and Merrin, 2009).

The null hypothesis that CIT positions do not impact daily returns in the data-defined roll period for CITs is rejected at the $5 \%$ level in 5 of the 12 markets and estimated cumulative impacts are negative in all 12 markets; the opposite of the expected outcome if CIT rolling activity simultaneously pressures nearby prices downward and first deferred prices upward. 
These results imply that CIT positions contribute to narrowing spreads between agricultural futures contracts. Additional tests indicate that the impact of CIT position changes on implied volatility during roll periods is negligible.

In sum, the results of this study add to the growing body of literature indicating that buying pressure from financial index investment in recent years did not cause massive bubbles in agricultural futures prices. The Masters Hypothesis is simply not a valid characterization of reality. This is not to say that the large influx of index investment did not have any impact in agricultural futures markets. We find some evidence that index investment may have resulted in a very slight upward pressure on futures prices before expiration and contributed to a small narrowing of price spreads during the period when index investors roll trades across futures contracts. The upward pressure on agricultural futures prices before expiration can be explained as either a temporary order flow impact (Henderson, Pearson, and Wang, 2012) or a re-pricing of risk (Hamilton and $\mathrm{Wu}, 2012$ ). The narrowing of spreads is likely due to a "sunshine trading effect" (Admati and Pfleiderer, 1991) where the preannouncement of CIT rolling activities coordinates the supply and demand of liquidity and reduces trading costs. These conclusions are consistent with the argument of Irwin and Sanders (2012b) that index investment may have several long-lasting and beneficial economic impacts, including a decrease in the cost of hedging for traditional physical market participants, a dampening of price volatility, and better integration of agricultural futures markets with financial markets. Finally, it should be noted that the results of this study do not rule out the possibility of small and short-lived bubble components in agricultural futures prices which are not associated with commodity index investment. Important implications for public policy follow from the conclusion that the Masters Hypothesis is not valid. First, new limits on speculation in agricultural futures markets are not 
grounded in well-established empirical findings and could impede the price discovery and riskshifting functions of these markets. Second, the focus on speculation has wasted precious time, attention, and effort that could be more productively directed towards the multiple challenges that global agriculture will face in the coming decades. The recent effort to put these challenges on the political agenda of international organizations such as the G-20 is an encouraging start (Blas, 2012). 


\section{References}

Acharya, V.V., L.A. Lochstoer, and T. Ramadorai. "Limits to Arbitrage and Hedging: Evidence from Commodity Markets.” Working Paper, London Business School, 2010.

Adammer, P., M.T. Bohl, and P.M. Stephan. "Speculative Bubbles in Agricultural Prices." Working Paper, Department of Economics, Westphalian Wilhelminian University of Munster, 2011.

Admati, A.R., and P. Pfleiderer. "Sunshine Trading and Financial Market Equilibrium.” Review of Financial Studies 4(1991):443-481.

Bellemare, M.F. “Rising Food Prices, Food Price Volatility, and Political Unrest.” Working Paper, Sanford School of Public Policy, Duke University, 2012.

Bessembinder, H., A. Carrion, L. Tuttle, and K. Venkataraman. "Predatory or Sunshine Trading? Evidence from Crude Oil ETF Rolls.” Working Paper, Department of Finance, University of Utah, 2012.

Blas, J. "Food Prices: Leaders Seek a Long-Term Solution to Hunger Pains." Financial Times, June 18, 2012. (http://www.ft.com/intl/cms/s/0/a6137e70-b15e-11e1-980000144feabdc0.html\#axzz1yBlAAZ4Z)

Brunetti, C, B. Buyuksahin, and J.H. Harris. "Speculators, Prices, and Market Volatility." Working Paper, Carey Business School, John Hopkins University, 2011.

Brunetti, C., and D. Reiffen. "Commodity Index Trading and Hedging Costs." Finance and Economics Discussion Series 2011-57, Divisions of Research and Statistics and Monetary Affairs, Federal Reserve Board, 2011.

Bryant, H., D.A. Bessler, and M.S. Haigh. "Causality in Futures Markets” Journal of Futures Markets 26(2006):1039-1057.

Buyuksahin, B., and M.A. Robe. "Speculators, Commodities, and Cross-Market Linkages." Working Paper, Kogod School of Business, American University, 2010.

Capelle-Blancard, G., and D. Coulibaly. "Index Trading and Agricultural Commodity Prices: A Panel Granger Causality Analysis.” Economie Internationale 126(2011):51-72.

Cheng, I.H., A. Kirilenko, and W. Xiong. "Convective Risk Flows in Commodity Futures Markets.” Working Paper, Department of Economics, Princeton University, 2012. 
Commodity Futures Trading Commission (CFTC). "Commodity Futures Trading Commission Actions in Response to the "Comprehensive Review of the Commitments of Traders Reporting Program (June 21, 2006).” 2006. (http://www.cftc.gov/ucm/groups/public/@,commitmentsoftraders/documents/file/noticeo nsupplementalcotrept.pdf)

Commodity Futures Trading Commission (CFTC). "Large Trader Reporting Program.” 2012a. (http://www.cftc.gov/IndustryOversight/MarketSurveillance/LargeTraderReportingProgr $\underline{\text { am/index.htm) }}$

Commodity Futures Trading Commission (CFTC). "About the Commitments of Traders." 2012b. (http://www.cftc.gov/marketreports/commitmentsoftraders/cot about.html)

De Long, J.B., A. Shleifer, L.H. Summers, and R.J. Waldmann. "Noise Trader Risk in Financial Markets.” Journal of Political Economy 98(1990):703-38.

De Schutter, O. "Food Commodities Speculation and Food Price Crises: Regulation to Reduce the Risks of Price Volatility." Briefing Note 02 by the United Nations Special Rapporteur on the Right to Food, 2010. (http://www.srfood.org/images/stories/pdf/otherdocuments/20102309 briefing note 02 en ok.pdf)

Dwyer, A., J. Holloway, and M. Wright. "Commodity Market Financialisation: A Closer Look at the Evidence.” Reserve Bank of Australia Bulletin, March Quarter, 2012.

Enders, W. Applied Econometric Time Series. John Wiley and Sons: New York, NY, 1995.

Engelke, L., and J.C. Yuen. "Types of Commodity Investments.” In The Handbook of Commodity Investing, F.J. Fabozzi, F. Roland, and D.G. Kaiser, eds. John Wiley and Sons: New York, NY, 2008.

Etula, E. "Broker-Dealer Risk Appetite and Commodity Returns.” Staff Report No. 406, Federal Reserve Bank of New York, 2010.

Fama, E. F. "Efficient Capital Markets: A Review of Theory and Empirical Work." Journal of Finance 25(1970):383-417.

Fattouh, B., L. Kilian, and L. Mahadeva. "The Role of Speculation in Oil Markets: What Have We Learned So Far?” Working Paper, Oxford Institute for Energy Studies, 2012.

Fenton, J., and G. Martinaitas. "Large Trader Reporting: The Great Equalizer." Futures Industry, July/August 2005, pp. 34-39.

G-20. "Report of the G20 Study Group on Commodities." 2011. (http://www.g20.org/images/stories/canalfinan/gexpert/01reportG20.pdf) 
Garcia, P., S.H. Irwin, and A. Smith. "Futures Market Failure?" Working Paper, Department of Agricultural and Consumer Economics, University of Illinois at Urbana-Champaign, 2012.

Gilbert, C.L. "Speculative Influences on Commodity Futures Prices, 2006-2008.” Working Paper, Department of Economics, University of Trento, 2009.

Gilbert, C.L. "How to Understand High Food Prices. Journal of Agricultural Economics 61(2010):398-425.

Gilbert, C.L., and S. Pfuderer. "Index Funds Do Impact Agricultural Prices." Working Paper, Department of Economics, University of Trento, 2012.

Grosche, S. "Limitations of Granger Causality Analysis to Assess the Price Effects from the Financialization of Agricultural Commodity Markets under Bounded Rationality." Discussion Paper 2012:1, Institute for Food and Resource Economics, University of Bonn, 2012.

Grossman, S.J. “An Analysis of "Insider Trading” on Futures Markets.” Journal of Business 59(1986, part 2):S129-46

Grossman, S.J., and M.H. Miller. "Liquidity and Market Structure." Journal of Finance 43(1988):617-633.

Gutierrez, L. "Looking for Rational Bubbles in Agricultural Commodity Markets." Paper Presented at the European Agricultural Economics Congress, Zurich, Switzerland, August 30-September 2, 2011.

Hamilton, J.D. Time Series Analysis. Princeton University Press: Princeton, NJ, 1994.

Hamilton, J.D., and J.C. Wu. "Risk Premia in Crude Oil Futures Prices.” Working Paper, Department of Economics, University of California-San Diego, 2011.

Hamilton, J.D., and J.C. Wu. "Effects of Index-Fund Investing on Commodity Futures Prices." Working Paper, Department of Economics, University of California-San Diego, 2012.

Harvey, A.C. The Econometric Analysis of Time Series, Second Edition. MIT Press: Cambridge, MA, 1991.

Henderson, B.J., N.D. Pearson, and L. Wang. "New Evidence on the Financialization of Commodity Markets.” Working Paper, Department of Finance, George Washington University, 2012. 
Herman, M.O., R. Kelly, and R. Nash. "Not a Game: Speculation vs. Food Security.” Oxfam Issues Briefing, October 3, 2011. (http://www.oxfam.org/sites/www.oxfam.org/files/ibspeculation-vs-food-security-031011-en.pdf)

Hoover, K.D. Causality in Macroeconomics. Cambridge University Press: Cambridge, UK, 2001.

Hull, J.C. Options, Futures, and Other Derivatives, Fourth Edition. Prentice Hall: Upper Saddle River, NJ, 2000.

Irwin, S.H., P. Garcia, D.L. Good, and E.L. Kunda. "Spreads and Non-Convergence in CBOT Corn, Soybean, and Wheat Futures: Are Index Funds to Blame?" Applied Economic Perspectives and Policy 33(2011):116-142.

Irwin, S.H., and D.R. Sanders. "Index Funds, Financialization, and Commodity Futures Markets" Applied Economic Perspectives and Policy 33(2011):1-31.

Irwin, S.H., and D.R. Sanders. "Testing the Masters Hypothesis in Commodity Futures Markets." Energy Economics 34(2012a):256-269.

Irwin, S.H., and D.R. Sanders. "Financialization and Structural Change in Commodity Futures Markets." Journal of Agricultural and Applied Economics 44(2012b):371-396.

Irwin, S.H., and D.R. Sanders. "A Reappraisal of Investing in Commodity Futures Markets." Applied Economic Perspectives and Policy 34(2012c):515-530.

Irwin, S.H., D.R. Sanders, and R.P. Merrin. "Devil or Angel? The Role of Speculation in the Recent Commodity Price Boom (and Bust)." Journal of Agricultural and Applied Economics 41(2009):393-402.

Janzen, J.P., A.D. Smith, and C.A. Carter. "Commodity Price Comovement: The Case of Cotton." Proceedings of the 2012 NCCC-134 Conference on Applied Commodity Price Analysis, Forecasting, and Market Risk Management. (http://www.farmdoc.illinois.edu/nccc134/conf_2012/pdf/confp02-12.pdf)

Kemp, J. "Volatility Indices Round out Markets." Commodities Now, March 9, 2010. (http://www.commodities-now.com/news/portfolio-management/1978-volatility-indicesround-out-commodity-markets.html)

Masters, M.W. "Testimony before the Committee on Homeland Security and Governmental Affairs, United States Senate." May 20, 2008. (http://hsgac.senate.gov/public/_files/052008Masters.pdf). 
Masters, M.W. "Testimony before the Commodity Futures Trading Commission.” August 5, 2009.

(http://www.cftc.gov/ucm/groups/public/@newsroom/documents/file/hearing080509_ma sters.pdf).

Masters, M.W., and A.K. White. "The Accidental Hunt Brothers: How Institutional Investors are Driving up Food and Energy Prices." 2008. (http://www.loe.org/images/content/080919/Act1.pdf)

Meyer, G., and C. Cui. "U.S. Oil Fund Finds Itself at the Mercy of Traders." The Wall Street Journal, March 6, 2009. (http://online.wsj.com/article/SB123629874701846317.html)

Mou, Y. "Limits to Arbitrage and Commodity Index Investment: Front-Running the Goldman Roll.” Working Paper, Columbia School of Business, 2010.

Newbold, P. "Causality Testing in Economics." In Time Series Analysis: Theory and Practice I, O.D. Anderson ed., pp. 701-16. North Holland Publishing Company: Amsterdam, NL, 1982.

Parkinson, M. "The Extreme Value Method for Estimating the Variance of the Rate of Return." Journal of Business 53(1980):61-65.

Phillips, P.C.B., and J. Yu. "Dating the Timeline of Financial Bubbles during the Subprime Crisis." Cowles Foundation Discussion Paper No. 1770, Yale University. 2010.

Pirrong, C. “No Theory? No Evidence? No Problem!” Regulation 33(2010):38-44.

Robles, M., M. Torero, and J. von Braun. "When Speculation Matters." International Food Policy Research Institute, IFPRI Issue Brief 57, 2009. (http://www.ifpri.org/publication/when-speculation-matters)

Sanders, D.R., and S.H. Irwin. "A Speculative Bubble in Commodity Futures Prices? CrossSectional Evidence.” Agricultural Economics 41(2010):25-32.

Sanders, D.R., and S.H. Irwin. "New Evidence on the Impact of Index Funds in U.S. Grain Futures Markets." Canadian Journal of Agricultural Economics 59(2011a):519-32.

Sanders, D.R., and S.H. Irwin. "The Impact of Index Funds in Commodity Futures Markets: A Systems Approach.” Journal of Alternative Investments 14(2011b):40-49.

Sanders, D.R., S.H. Irwin, and R.P. Merrin. "Smart Money? The Forecasting Ability of CFTC Large Traders." Journal of Agricultural and Resource Economics 34(2009):276-296.

Sanders, D.R., S.H. Irwin, and R.P. Merrin. "The Adequacy of Speculation in Agricultural Futures Markets: Too Much of a Good Thing?" Applied Economics Perspectives and Policy 32(2010):77-94. 
Singleton, K.J. "Investor Flows and the 2008 Boom/Bust in Oil Prices. Working Paper, Graduate School of Business, Stanford University, 2011.

Stoll, H.R., and R.E.Whaley. "Commodity Index Investing and Commodity Futures Prices." Journal of Applied Finance 20(2010):7-46.

Summers, L.H. "Does the Stock Market Rationally Reflect Fundamental Values.” Journal of Finance 41(1986):591-601.

Tang, K., and W. Xiong. "Index Investing and the Financialization of Commodities.” Working Paper No. 16385, National Bureau of Economic Research, 2010.

United Nations Conference on Trade and Development (UNCTAD). "Price Formation in Financialized Commodity Markets: The Role of Information.” 2011. (http://unctad.org/en/docs/gds20111_en.pdf)

United States Senate, Permanent Subcommittee on Investigations (USS/PSI). Excessive Speculation in the Wheat Market. U.S. Government Printing Office: Washington, D.C., 2009.

The World Bank (WB). "Food Price Hike Drives 44 Million People into Poverty." Press Release No. 2011/333/PREM, February 15, 2011. (http://web.worldbank.org/WBSITE/EXTERNAL/NEWS/0, contentMDK:22833439 pag ePK:64257043 piPK:437376 theSitePK:4607,00.html)

Wright, B. "The Economics of Grain Price Volatility." Applied Economic Perspectives and Policy 33(2011):32-58. 
Table 1. Average Daily Net Futures Positions of Commodity Index Traders (CITs) in 12 Agricultural Futures Markets, All Contracts, 2000-2009

\begin{tabular}{|c|c|c|c|c|c|c|c|c|c|c|}
\hline \multirow[b]{2}{*}{ Market } & \multicolumn{10}{|c|}{ Year } \\
\hline & 2000 & 2001 & 2002 & 2003 & 2004 & 2005 & 2006 & 2007 & 2008 & 2009 \\
\hline \multicolumn{11}{|c|}{ Panel A: Number of Contracts } \\
\hline Cocoa & 2,208 & 1,447 & 1,892 & 2,612 & 11,549 & 7,483 & 13,272 & 17,534 & 23,612 & 16,195 \\
\hline Coffee & 2,728 & 1,475 & 2,867 & 6,916 & 21,735 & 23,114 & 33,862 & 42,716 & 54,434 & 38,165 \\
\hline Cotton & 4,967 & 4,009 & 5,579 & 7,863 & 16,132 & 38,696 & 71,430 & 87,229 & 95,249 & 65,637 \\
\hline Sugar & 12,898 & 10,059 & 17,659 & 23,497 & 61,931 & 98,672 & 136,135 & 230,434 & 309,598 & 180,138 \\
\hline Feeder Cattle & 1 & 101 & 1,557 & 1,933 & 2,838 & 4,362 & 6,562 & 8,315 & 8,265 & 6,210 \\
\hline Lean Hogs & 7,858 & 6,479 & 8,654 & 10,546 & 26,801 & 43,871 & 76,923 & 80,275 & 100,138 & 56,472 \\
\hline Live Cattle & 22,360 & 12,779 & 12,067 & 13,941 & 33,118 & 52,931 & 86,152 & 112,310 & 128,549 & 90,465 \\
\hline Corn & 28,732 & 30,217 & 48,209 & 53,656 & 117,364 & 233,142 & 393,954 & 357,482 & 358,979 & 289,860 \\
\hline Soybeans & 6,509 & 4,920 & 9,563 & 28,279 & 36,692 & 76,884 & 114,591 & 147,449 & 143,982 & 122,437 \\
\hline Soybean Oil & -122 & 1 & 949 & 1,402 & 10,773 & 38,030 & 65,801 & 72,351 & 68,371 & 54,855 \\
\hline Wheat CBOT & 20,178 & 18,704 & 21,439 & 25,702 & 56,682 & 134,408 & 195,194 & 185,341 & 165,968 & 151,227 \\
\hline Wheat KCBOT & 5,591 & 5,777 & 7,921 & 9,543 & 14,971 & 18,210 & 25,480 & 31,372 & 26,156 & 26,178 \\
\hline
\end{tabular}

Panel B: Percent of Total Open Interest

\begin{tabular}{|c|c|c|c|c|c|c|c|c|c|}
\hline Cocoa & 2 & 1 & 2 & 3 & 11 & 6 & 10 & 12 & 16 \\
\hline Coffee & 6 & 3 & 4 & 9 & 23 & 24 & 31 & 28 & 37 \\
\hline Cotton & 8 & 6 & 8 & 10 & 20 & 37 & 45 & 41 & 43 \\
\hline Sugar & 7 & 7 & 9 & 12 & 21 & 24 & 28 & 33 & 37 \\
\hline Feeder Cattle & 0 & 1 & 12 & 11 & 17 & 17 & 22 & 29 & 27 \\
\hline Lean Hogs & 16 & 15 & 26 & 25 & 34 & 43 & 48 & 44 & 47 \\
\hline Live Cattle & 18 & 11 & 12 & 13 & 29 & 35 & 38 & 45 & 48 \\
\hline Corn & 7 & 7 & 10 & 13 & 19 & 33 & 32 & 28 & 29 \\
\hline Soybeans & 4 & 3 & 5 & 12 & 16 & 28 & 31 & 29 & 33 \\
\hline Soybean Oil & 0 & 0 & 1 & 1 & 7 & 24 & 28 & 25 & 26 \\
\hline Wheat CBOT & 15 & 14 & 19 & 25 & 37 & 55 & 45 & 46 & 48 \\
\hline Wheat KCBOT & 8 & 8 & 11 & 16 & 22 & 20 & 18 & 24 & 26 \\
\hline
\end{tabular}

Notes: Data for 2009 end on September 29, 2009. Positions of commodity index traders (CITs) are aggregated across all contract maturity months on a given day and exclude options positions. 
Table 2. Granger Causality Test Results for the Null Hypothesis that the Change in Aggregate Commodity Index Trader (CIT) Net Position Does Not Cause Returns, January 2004 through September 2009

$$
R_{t, k}=\alpha_{t, k}+\sum_{i=1}^{m} \gamma_{i, k} R_{t-i, k}+\sum_{j=1}^{n} \beta_{j, k} X_{t-j, k}+\varepsilon_{t, k} \text { for each market, } k, \text { and time, } t
$$

\begin{tabular}{|c|c|c|c|c|c|}
\hline Market, $\mathrm{k}$ & $\mathrm{m}, \mathrm{n}$ & $\begin{array}{r}\mathrm{p} \text {-value } \\
\beta_{j}=0, \forall j\end{array}$ & $\begin{array}{c}\text { Estimate } \\
\sum \beta_{j}\end{array}$ & $\begin{array}{c}\mathrm{p} \text {-value } \\
\sum \beta_{j}=0\end{array}$ & $\begin{array}{c}\text { One St. Dev. } \\
\text { Impact }\end{array}$ \\
\hline Cocoa & 1,1 & 0.512 & 0.00009 & & 0.034 \\
\hline Coffee & 1,1 & 0.683 & 0.00005 & & 0.021 \\
\hline Cotton & 1,1 & 0.563 & -0.00004 & & -0.024 \\
\hline Sugar & 1,1 & 0.804 & -0.00001 & & -0.023 \\
\hline Feeder Cattle & 1,1 & 0.040 & -0.00029 & & -0.032 \\
\hline Lean Hogs & 2,1 & 0.000 & -0.00017 & & -0.127 \\
\hline Live Cattle & 1,2 & 0.890 & 0.00000 & 0.92 & -0.002 \\
\hline Corn & 1,1 & 0.259 & -0.00001 & & -0.027 \\
\hline Soybeans & 1,1 & 0.288 & 0.00003 & & 0.032 \\
\hline Soybean Oil & 1,1 & 0.258 & -0.00004 & & -0.029 \\
\hline Wheat CBOT & 1,1 & 0.051 & -0.00003 & & -0.042 \\
\hline \multirow[t]{3}{*}{ Wheat KCBOT } & 1,1 & 0.021 & -0.00011 & & -0.042 \\
\hline & & p-value & Estimate & p-value & \\
\hline & & $\beta_{j, k}=0, \forall j, k$ & $\sum \sum \beta_{j, k}$ & $\sum \sum \beta_{j, k}=0$ & \\
\hline System & & 0.003 & -0.0005 & 0.036 & \\
\hline
\end{tabular}

Notes: $R$ is nearby return and $X$ is change in aggregate CIT positions. The models are estimated across the $K$ markets as an SUR system. The intercepts are estimated as a single pooled parameter across all markets. The number of observations per commodity is 1,447 . Bold values are statistically significant at the $5 \%$ level. 
Table 3. Granger Causality Test Results for the Null Hypothesis that the Change in Aggregate Commodity Index Trader (CIT) Net Position Does Not Cause Implied Volatility, January 2004 through September 2009

$$
V_{t, k}=\alpha_{t, k}+\sum_{i=1}^{m} \gamma_{i, k} V_{t-i, k}+\sum_{j=1}^{n} \beta_{j, k} X_{t-j, k}+D u m+\varepsilon_{t, k} \text { for each market, } k \text {, and time, } t
$$

\begin{tabular}{|c|c|c|c|c|c|}
\hline Market, $\mathrm{k}$ & $\mathrm{m}, \mathrm{n}$ & $\begin{array}{c}\mathrm{p} \text {-value } \\
\beta_{j}=0, \forall j\end{array}$ & $\begin{array}{l}\text { Estimate } \\
\sum \beta_{j}\end{array}$ & $\begin{array}{l}\text { p-value } \\
\sum \beta_{j}=0\end{array}$ & $\begin{array}{c}\text { One St. Dev. } \\
\text { Impact }\end{array}$ \\
\hline Cocoa & 5,1 & 0.750 & -0.000003 & & -0.001 \\
\hline Coffee & 2,1 & 0.750 & -0.000003 & & -0.001 \\
\hline Cotton & 5,1 & 0.750 & -0.000003 & & -0.002 \\
\hline Sugar & 4,1 & 0.750 & -0.000003 & & -0.008 \\
\hline Feeder Cattle & 5,1 & 0.750 & -0.000003 & & -0.0004 \\
\hline Lean Hogs & 2,1 & 0.750 & -0.000003 & & -0.003 \\
\hline Live Cattle & 4,1 & 0.750 & -0.000003 & & -0.002 \\
\hline Corn & 1,1 & 0.750 & -0.000003 & & -0.009 \\
\hline Soybeans & 1,1 & 0.750 & -0.000003 & & -0.004 \\
\hline Soybean Oil & 3,1 & 0.750 & -0.000003 & & -0.002 \\
\hline Wheat CBOT & 3,1 & 0.750 & -0.000003 & & -0.005 \\
\hline \multirow[t]{3}{*}{ Wheat KCBOT } & 4,1 & 0.75 & -0.000003 & & -0.001 \\
\hline & & p-value & Estimate & $\mathrm{p}$-value & \\
\hline & & $\beta_{j, k}=0, \forall j, k$ & $\sum \sum \beta_{j, k}$ & $\sum \sum \beta_{j, k}=0$ & \\
\hline System & & 0.750 & -0.000003 & 0.750 & \\
\hline
\end{tabular}

Notes: $V$ is nearby implied volatility and $X$ is change in aggregate CIT positions. The models are estimated across the $K$ markets as an SUR system. Dummy variables for months are used. Coefficients for the first lag of CIT positions and May through October dummy variablesare are estimated as a single pooled parameter across all markets. The number of observations per commodity is 1,447 . Bold values are statistically significant at the $5 \%$ level. 
Table 4. Granger Causality Test Results for the Null Hypothesis that the Change in Returns Does Not Cause the Change in Aggregate Commodity Index Trader (CIT) Net Position, January 2004 through September 2009

$$
X_{t, k}=\alpha_{t, k}+\sum_{i=1}^{m} \gamma_{i, k} R_{t-i, k}+\sum_{j=1}^{n} \beta_{j, k} X_{t-j, k}+\varepsilon_{t, k} \text { for each market, } k, \text { and time, } t
$$

\begin{tabular}{|c|c|c|c|c|c|}
\hline Market, k & $\mathrm{m}, \mathrm{n}$ & $\begin{array}{c}\text { p-value } \\
\gamma_{i}=0, \forall i\end{array}$ & ${ }^{\text {Estimate }}$ & $\begin{array}{l}\mathrm{p} \text {-value } \\
\sum \gamma_{i}=0\end{array}$ & $\begin{array}{c}\text { One St. Dev. } \\
\text { Impact }\end{array}$ \\
\hline Cocoa & 5,2 & 0.053 & 18.14 & 0.080 & 37 \\
\hline Coffee & 1,2 & 0.053 & 9.84 & & 20 \\
\hline Cotton & 1,4 & 0.028 & 16.51 & & 31 \\
\hline Sugar & 1,2 & 0.219 & 33.34 & & 68 \\
\hline Feeder Cattle & 1,2 & 0.425 & 2.32 & & 2 \\
\hline Lean Hogs & 1,3 & 0.016 & 24.27 & & 36 \\
\hline Live Cattle & 1,3 & 0.024 & 30.94 & & 31 \\
\hline Corn & 1,3 & 0.000 & 132.13 & & 266 \\
\hline Soybeans & 2,2 & 0.000 & 117.69 & 0.000 & 220 \\
\hline Soybean Oil & 1,3 & 0.023 & 21.43 & & 40 \\
\hline Wheat CBOT & 1,3 & 0.000 & 62.66 & & 138 \\
\hline \multirow[t]{3}{*}{ Wheat KCBOT } & 1,1 & 0.004 & 14.34 & & 29 \\
\hline & & $\mathrm{p}$-value & Estimate & $\mathrm{p}$-value & \\
\hline & & $\gamma_{i, k}=0, \forall i, k$ & $\sum \sum \gamma_{i, k}$ & $\sum \sum \gamma_{i, k}=0$ & \\
\hline System & & 0.000 & 483.61 & 0.000 & \\
\hline
\end{tabular}

Notes: $R$ is nearby return and $X$ is change in aggregate CIT positions. The models are estimated across the $K$ markets as an SUR system. Dummy variables for months are used. Intercepts and coefficients for the third lag of CIT positions are estimated as a single pooled parameter across all markets. The number of observations per commodity is 1,447 . Bold values are statistically significant at the $5 \%$ level. 
Table 5. Granger Causality Test Results for the Null Hypothesis that Implied Volatility Does Not Cause the Change in Aggregate Commodity Index Trader (CIT) Net Position, January 2004 through September 2009

$$
X_{t, k}=\alpha_{t, k}+\sum_{i=1}^{m} \gamma_{i, k} V_{t-i, k}+\sum_{j=1}^{n} \beta_{j, k} X_{t-j, k}+D u m+\varepsilon_{t, k} \text { for each market, } k, \text { and time, } t
$$

\begin{tabular}{|c|c|c|c|c|c|}
\hline Market, k & $\mathrm{m}, \mathrm{n}$ & $\begin{array}{c}\text { p-value } \\
\gamma_{i}=0, \forall i\end{array}$ & $\begin{array}{l}\text { Estimate } \\
\sum \gamma_{i}\end{array}$ & $\begin{array}{l}\text { p-value } \\
\sum \gamma_{i}=0\end{array}$ & $\begin{array}{c}\text { One St. Dev. } \\
\text { Impact }\end{array}$ \\
\hline Cocoa & 5,2 & 0.000 & -2.28 & 0.054 & -19 \\
\hline Coffee & 3,3 & 0.313 & -1.87 & 0.249 & -12 \\
\hline Cotton & 1,4 & 0.040 & -3.79 & & -30 \\
\hline Sugar & 1,2 & 0.004 & -21.08 & & -161 \\
\hline Feeder Cattle & 1,2 & 0.131 & 1.19 & & 6 \\
\hline Lean Hogs & 1,2 & 0.817 & 0.20 & & 3 \\
\hline Live Cattle & 1,3 & 0.134 & -4.71 & & -21 \\
\hline Corn & 5,3 & 0.000 & -4.86 & 0.480 & -42 \\
\hline Soybeans & 1,1 & 0.145 & -4.46 & & -36 \\
\hline Soybean Oil & 1,3 & 0.181 & -4.03 & & -24 \\
\hline Wheat CBOT & 2,1 & 0.000 & -9.52 & 0.009 & -86 \\
\hline \multirow[t]{3}{*}{ Wheat KCBOT } & 1,1 & 0.683 & 0.50 & & 4 \\
\hline & & p-value & Estimate & p-value & \\
\hline & & $\gamma_{i, k}=0, \forall i, k$ & $\sum \sum \gamma_{i, k}$ & $\sum \sum \gamma_{i, k}=0$ & \\
\hline System & & 0.000 & -48.94 & 0.000 & \\
\hline
\end{tabular}

Notes: $V$ is nearby implied volatility and $\mathrm{X}$ is change in aggregate CIT positions. The models are estimated across the $K$ markets as an SUR system. Dummy variables for months are used. Coefficients for the third lag of CIT positions and the fifth lag of implied volatility are estimated as a single pooled parameter across all markets. The number of observations per commodity is 1,447 . Bold values are statistically significant at the $5 \%$ level. 
Table 6. Granger Causality Test Results for the Null Hypothesis that the Change in Aggregate Commodity Index Trader (CIT) Net Position Does Not Cause Returns during Roll Windows, January 2004 through September 2009

$$
N R_{t}=\alpha_{t}+\sum_{i=1}^{m} \gamma_{i} N R_{t-i}+\sum_{j=1}^{n} \beta_{j} N X_{t-j}+\varepsilon_{t} \quad D R_{t}=\alpha_{t}+\sum_{i=1}^{m} \gamma_{i} D R_{t-i}+\sum_{j=1}^{n} \beta_{j} D X_{t-j}+\varepsilon_{t}
$$

\begin{tabular}{|c|c|c|c|c|c|c|}
\hline Market, k & $\mathrm{m}, \mathrm{n}$ & $\begin{array}{l}\mathrm{p} \text {-value } \\
\beta_{j}=0, \forall j\end{array}$ & $\begin{array}{c}\text { Estimate } \\
\sum \beta_{j}\end{array}$ & $\begin{array}{l}\text { p-value } \\
\sum \beta_{j}=0\end{array}$ & $\begin{array}{l}\text { One St. Dev. } \\
\text { Nearby Impact }\end{array}$ & $\begin{array}{c}\text { One St. Dev. } \\
\text { Deferred Impact }\end{array}$ \\
\hline Cocoa & 1,5 & 0.000 & -0.000026 & 0.143 & -0.02 & -0.02 \\
\hline Coffee & 1,5 & 0.857 & -0.000005 & 0.196 & -0.01 & -0.01 \\
\hline Cotton & 1,1 & 0.000 & -0.000044 & 0.000 & -0.10 & -0.10 \\
\hline Sugar & 1,4 & 0.490 & -0.000003 & 0.157 & -0.02 & -0.02 \\
\hline Feeder Cattle & 1,1 & 0.069 & -0.000022 & 0.069 & -0.01 & -0.01 \\
\hline Lean Hogs & 1,1 & 0.002 & -0.000013 & 0.002 & -0.04 & -0.04 \\
\hline Live Cattle & 1,1 & 0.001 & -0.000007 & 0.001 & -0.02 & -0.02 \\
\hline Corn & 1,5 & 0.633 & -0.000002 & 0.089 & -0.02 & -0.02 \\
\hline Soybeans & 2,1 & 0.704 & -0.000001 & 0.704 & 0.00 & 0.00 \\
\hline Soybean Oil & 1,1 & 0.560 & -0.000001 & 0.560 & 0.00 & 0.00 \\
\hline Wheat CBOT & 1,5 & 0.088 & -0.000004 & 0.037 & -0.02 & -0.02 \\
\hline Wheat KCBOT & 1,4 & 0.001 & -0.000035 & 0.017 & -0.03 & -0.03 \\
\hline
\end{tabular}

Notes: NR is nearby return, DR is first deferred return, NX is nearby change in CIT positions, DX is first deferred change in CIT positions, NX is the change in nearby CIT positions, and DX is the first deferred change in CIT positions. The models are estimated across the two contract maturities for each market as an SUR system. Observations vary by commodity due to differences in the number of maturing contracts, but each commodity has approximately 630 observations. Bold values are statistically significant at the $5 \%$ level. 
Table 7. Granger Causality Test Results for the Null Hypothesis that the Change in Aggregate Commodity Index Trader (CIT) Net Position Does Not Cause Implied Volatility during Roll Windows, January 2004 through September 2009

$$
N V_{t}=\alpha_{t}+\sum_{i=1}^{m} \gamma_{i} N V_{t-i}+\sum_{j=1}^{n} \beta_{j} N X_{t-j}+\varepsilon_{t} \quad D V_{t}=\alpha_{t}+\sum_{i=1}^{m} \gamma_{i} D V_{t-i}+\sum_{j=1}^{n} \beta_{j} D X_{t-j}+\varepsilon_{t}
$$

\begin{tabular}{|c|c|c|c|c|c|c|}
\hline Market, k & $\mathrm{m}, \mathrm{n}$ & $\begin{array}{l}\mathrm{p} \text {-value } \\
\beta_{j}=0, \forall j\end{array}$ & $\begin{array}{c}\text { Estimate } \\
\sum \beta_{j}\end{array}$ & $\begin{array}{c}\mathrm{p} \text {-value } \\
\sum \beta_{j}=0\end{array}$ & $\begin{array}{l}\text { One St. Dev. } \\
\text { Nearby Impact }\end{array}$ & $\begin{array}{l}\text { One St. Dev. } \\
\text { Deferred Impact }\end{array}$ \\
\hline Cocoa & 1,1 & 0.002 & 0.000393 & 0.000 & 0.33 & 0.29 \\
\hline Coffee & 1,1 & 0.749 & -0.000008 & 0.749 & -0.01 & -0.01 \\
\hline Cotton & 1,1 & 0.789 & -0.000003 & 0.789 & -0.01 & -0.01 \\
\hline Sugar & 1,1 & 0.423 & 0.000004 & 0.423 & 0.03 & 0.03 \\
\hline Feeder Cattle & 1,1 & 0.014 & 0.000093 & 0.014 & 0.03 & 0.03 \\
\hline Lean Hogs & 1,1 & 0.393 & 0.000014 & 0.393 & 0.04 & 0.04 \\
\hline Live Cattle & 1,1 & 0.224 & 0.000006 & 0.224 & 0.02 & 0.02 \\
\hline Corn & 1,1 & 0.959 & 0.000000 & 0.959 & 0.00 & 0.00 \\
\hline Soybeans & 2,1 & 0.717 & 0.000002 & 0.717 & 0.01 & 0.01 \\
\hline Soybean Oil & 1,1 & 0.759 & -0.000005 & 0.759 & -0.01 & -0.01 \\
\hline Wheat CBOT & 2,1 & 0.927 & 0.000000 & 0.927 & 0.00 & 0.00 \\
\hline Wheat KCBOT & 1,1 & 0.076 & 0.000048 & 0.076 & 0.05 & 0.04 \\
\hline
\end{tabular}

Notes: NV is nearby implied volatility, DV is first deferred implied volatility, NX is nearby change in CIT positions, DX is first deferred change in CIT positions, NX is the change in nearby CIT positions, and DX is the first deferred change in CIT positions. The models are estimated across the two contract maturities for each market as an SUR system. Observations vary by commodity due to differences in the number of maturing contracts, but each commodity has approximately 630 observations. Bold values are statistically significant at the $5 \%$ level. 
Table 8. Contemporaneous Correlation between Change in Commodity Index Trader (CIT) Position and Return or Implied Volatility during Alternative Roll Windows, January 2004 through September 2009

\begin{tabular}{|c|c|c|c|c|}
\hline \multirow[b]{2}{*}{ Market } & \multicolumn{2}{|c|}{ Extended Goldman Roll } & \multicolumn{2}{|c|}{ Goldman Roll } \\
\hline & Nearby & Deferred & Nearby & Deferred \\
\hline \multicolumn{5}{|c|}{ Panel A: Returns } \\
\hline Cocoa & -0.01 & 0.04 & -0.05 & -0.02 \\
\hline Coffee & -0.01 & 0.02 & -0.11 & 0.08 \\
\hline Cotton & 0.01 & 0.01 & 0.01 & 0.00 \\
\hline Sugar & -0.04 & 0.05 & -0.16 & 0.10 \\
\hline Feeder Cattle & 0.08 & -0.07 & 0.11 & -0.07 \\
\hline Lean Hogs & 0.02 & 0.05 & 0.12 & 0.04 \\
\hline Live Cattle & 0.06 & -0.04 & 0.19 & -0.16 \\
\hline Corn & 0.00 & 0.01 & 0.02 & -0.04 \\
\hline Soybeans & -0.04 & 0.05 & -0.16 & 0.10 \\
\hline Soybean Oil & -0.03 & 0.05 & -0.02 & -0.03 \\
\hline Wheat & 0.04 & 0.00 & 0.09 & -0.04 \\
\hline Wheat KS & 0.02 & 0.01 & 0.16 & -0.05 \\
\hline Average & 0.01 & 0.01 & 0.02 & -0.01 \\
\hline \multicolumn{5}{|c|}{ Panel B: Implied Volatility } \\
\hline Cocoa & -0.01 & -0.13 & -0.16 & -0.03 \\
\hline Coffee & 0.14 & -0.20 & 0.53 & -0.56 \\
\hline Cotton & 0.13 & -0.19 & 0.53 & -0.54 \\
\hline Sugar & 0.09 & -0.15 & 0.10 & -0.28 \\
\hline Feeder Cattle & 0.14 & -0.14 & 0.01 & -0.04 \\
\hline Lean Hogs & 0.00 & -0.08 & 0.09 & -0.33 \\
\hline Live Cattle & 0.14 & -0.16 & 0.55 & -0.52 \\
\hline Corn & 0.00 & -0.05 & 0.08 & -0.19 \\
\hline Soybeans & 0.09 & -0.15 & 0.10 & -0.28 \\
\hline Soybean Oil & 0.12 & -0.18 & 0.35 & -0.41 \\
\hline Wheat & 0.06 & -0.16 & 0.21 & -0.38 \\
\hline Wheat KS & 0.00 & -0.06 & 0.07 & -0.12 \\
\hline Average & 0.07 & -0.14 & 0.20 & -0.31 \\
\hline
\end{tabular}

Note: Bold values are statistically significant at the $5 \%$ level. 
Panel A: Number of Contracts

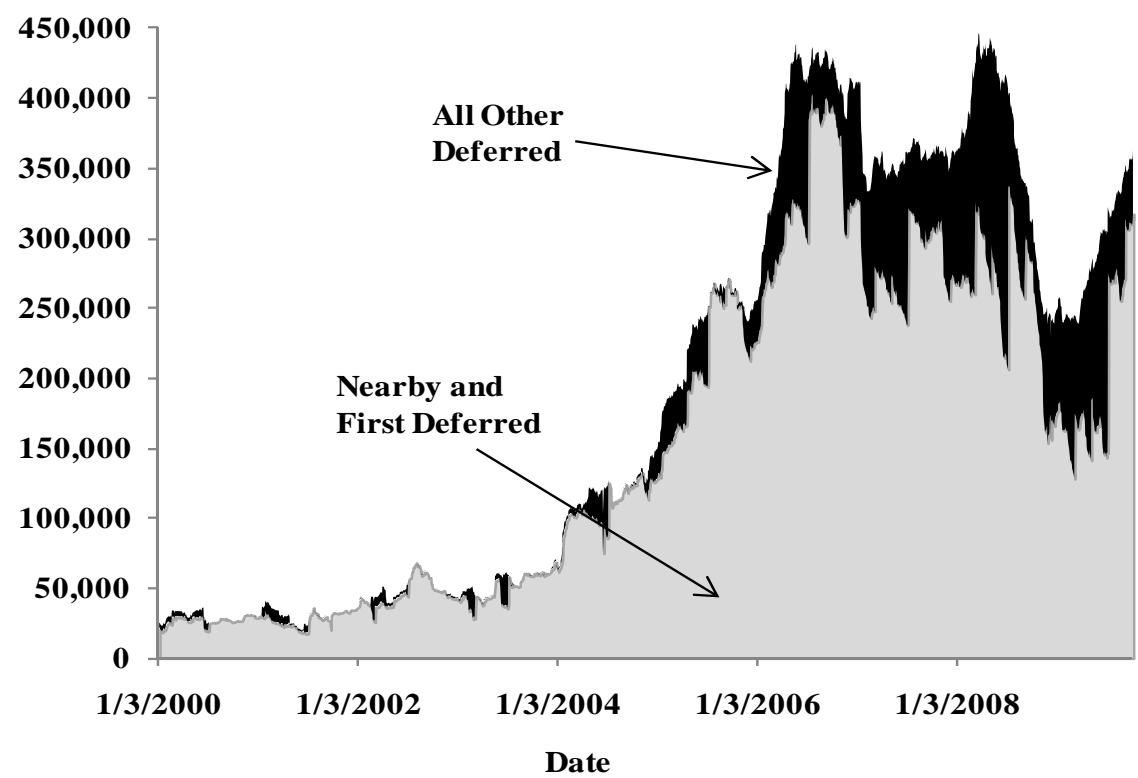

Panel B: Percent of Position in All Other Deferred Contracts

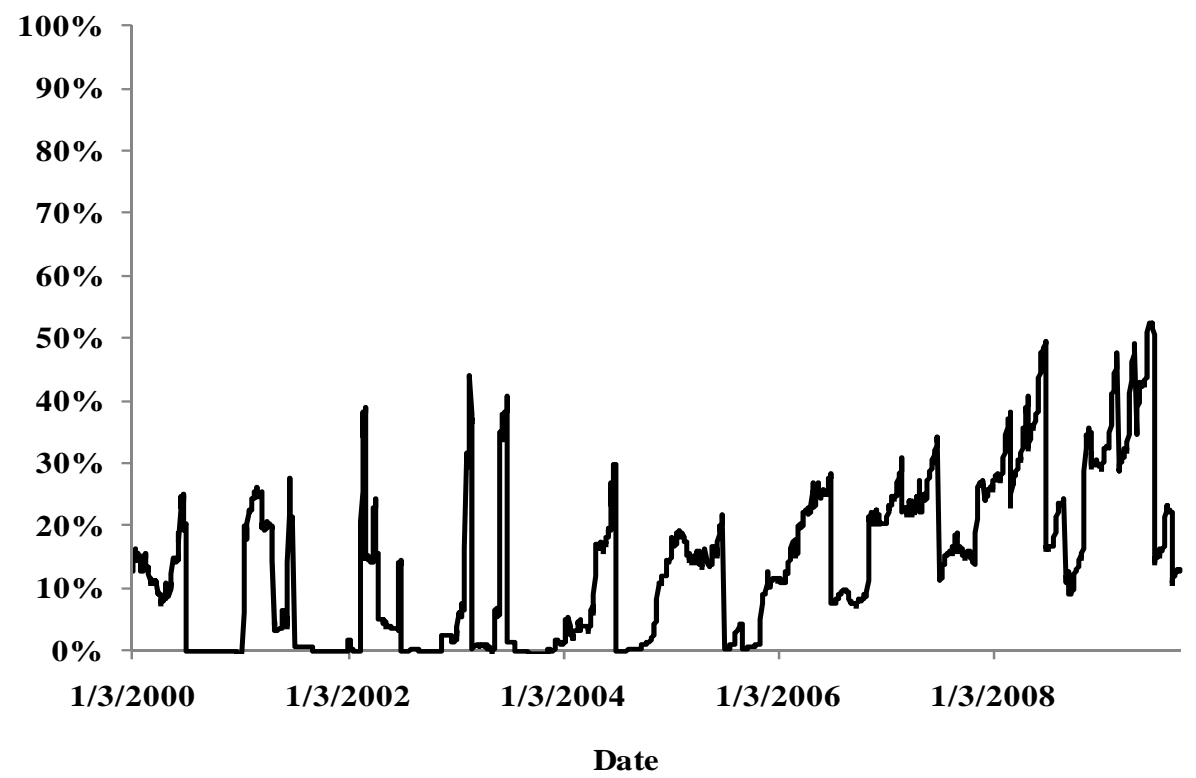

Figure 1. Composition of Daily Net Long Open Interest of Commodity Index Traders (CITs) in the Corn Futures Market, January 3, 2000 - September 29, 2009 
Panel A: Total and Contract-by-Contract Net Long Open Interest

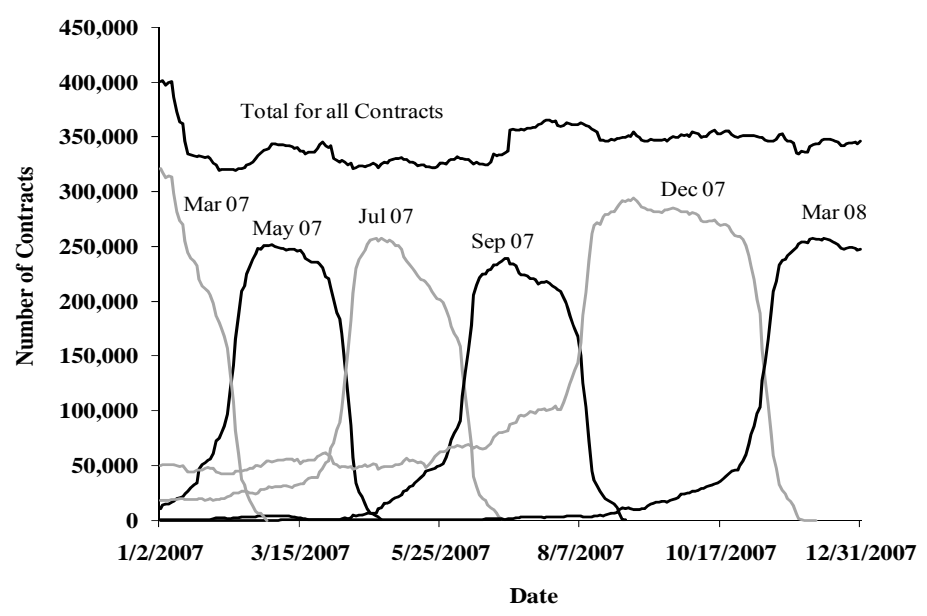

Panel B: Nearby and First Deferred Contract Net Long Open Interest

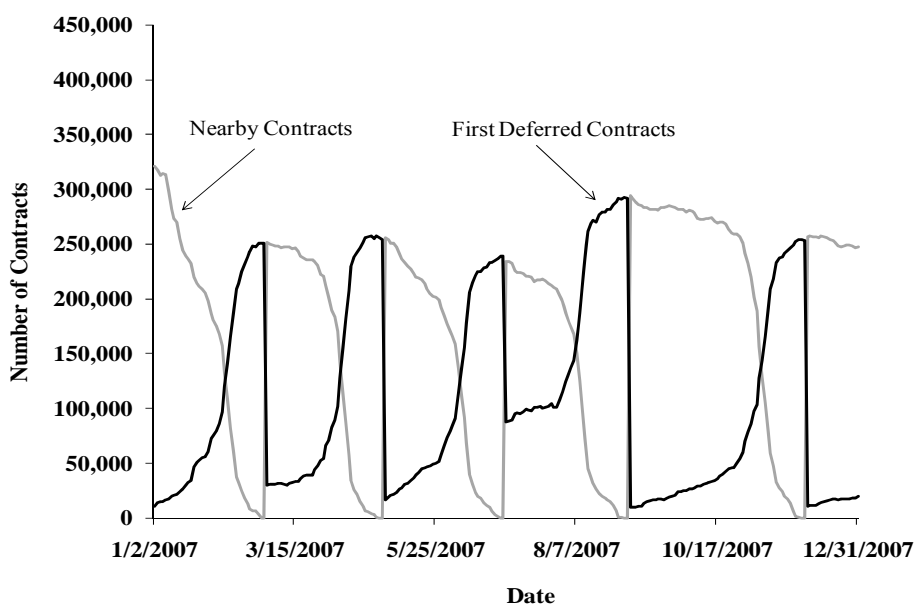

Panel C: Change in Nearby and First Deferred Net Long Open Interest

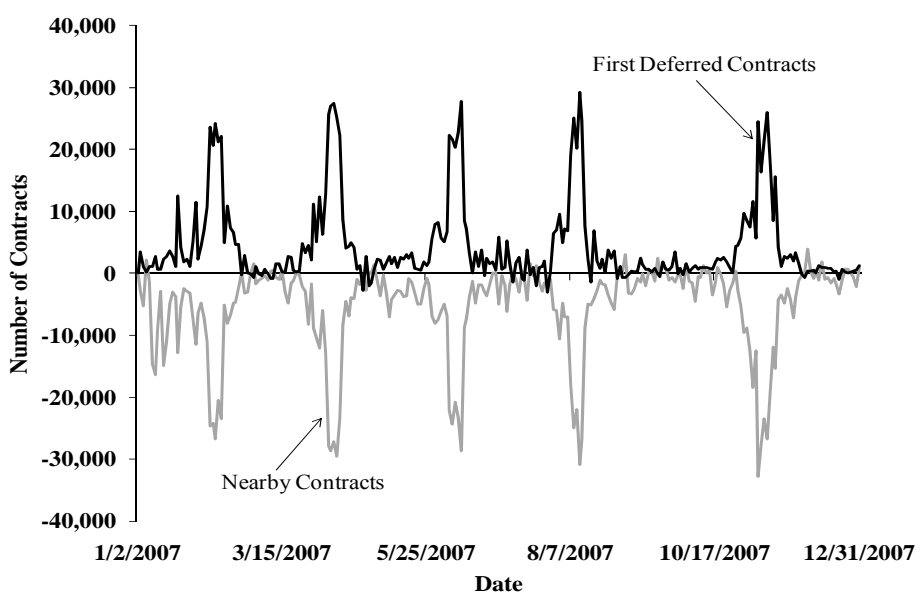

Figure 2. Level and Change in Daily Net Long Open Interest of Commodity Index Traders (CITs) in the Corn Futures Market, January 2, 2007 - December 31, 2007 


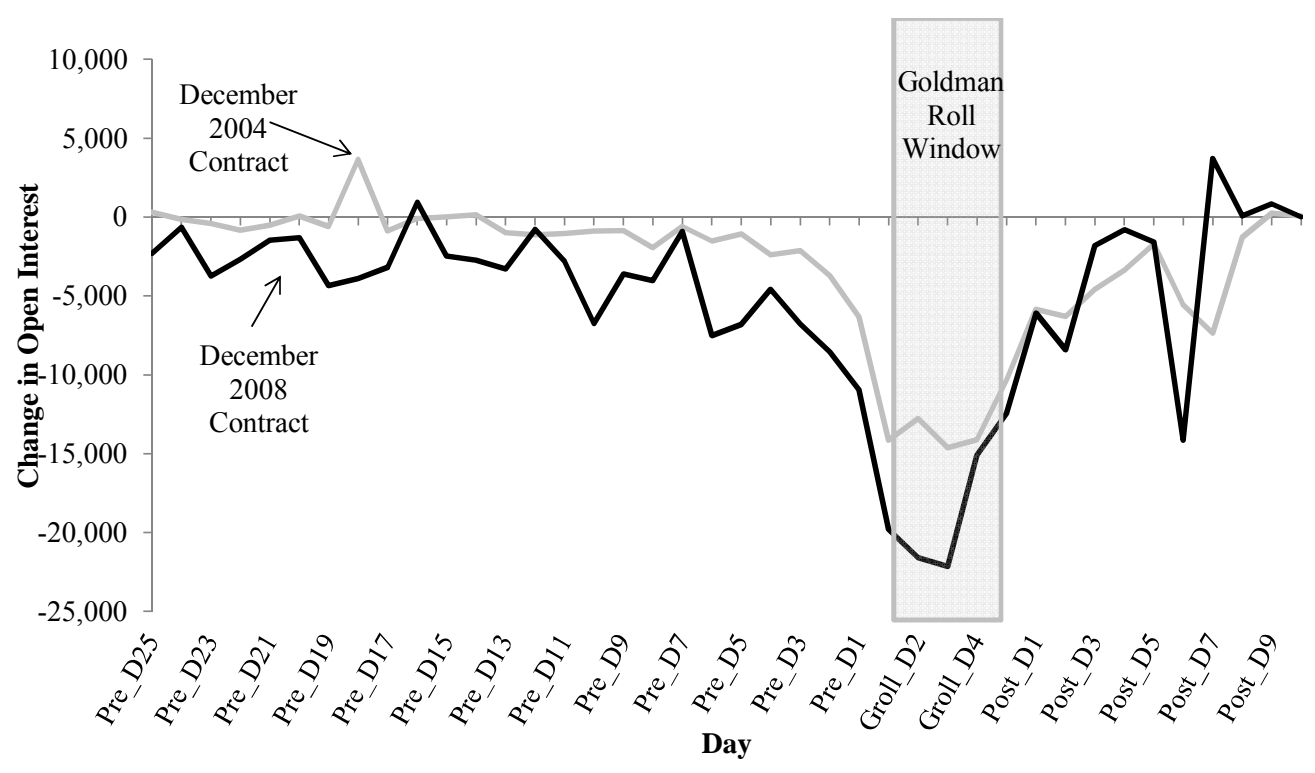

Figure 3. Commodity Index Trader (CIT) Change in Open Interest for the December 2004 and December 2008 Corn Futures Contracts 25 Days Before and 10 Days After the Goldman Roll Window

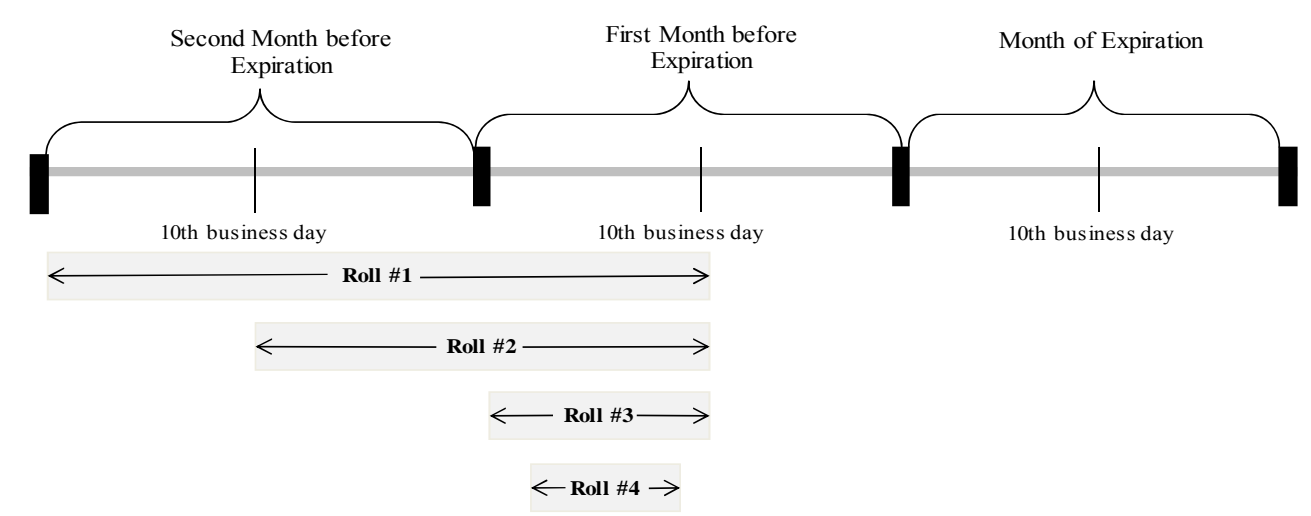

Figure 4. Alternative Roll Windows for Commodity Index Traders (CITs) 


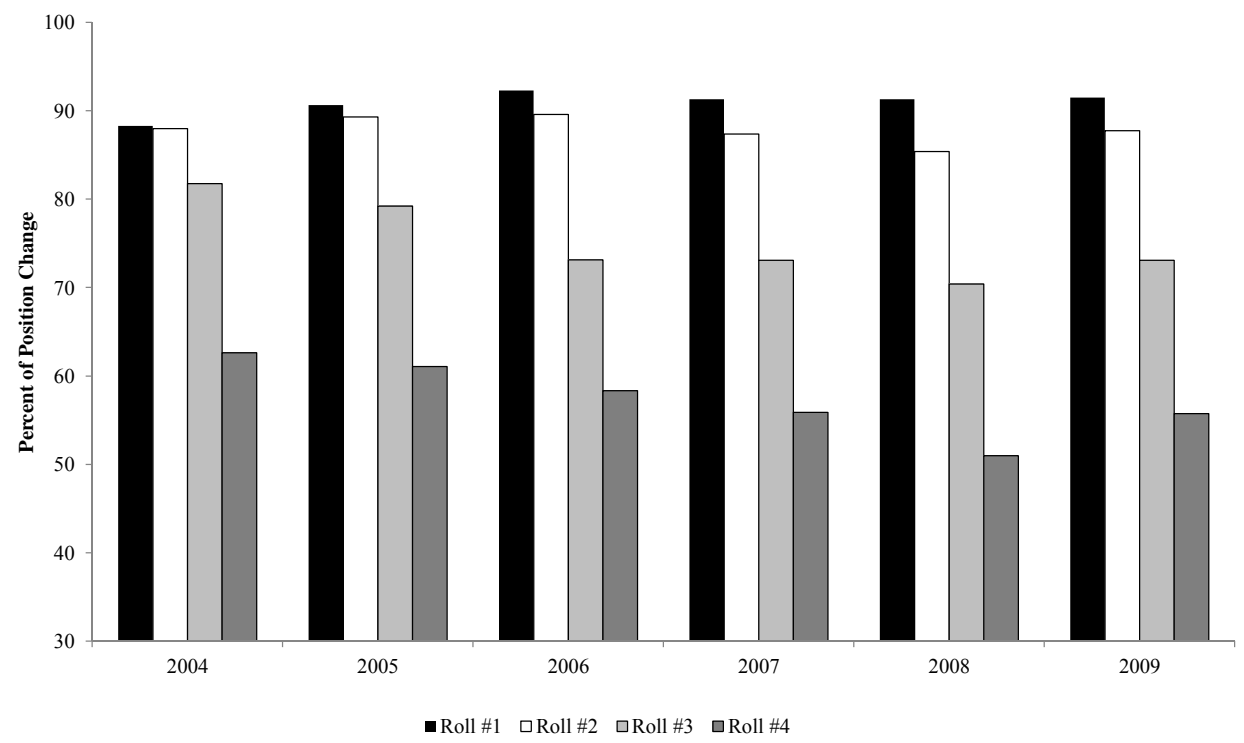

Note: See text and figure 4 for definitions of roll windows.

Figure 5. Proportion of Commodity Index Trader (CIT) Roll Activity in Alternative Roll Windows in 12 Agricultural Futures Markets, Annual Average Across All Markets and Contracts, 2004-2009 
Appendix 
Table A1. OLS Granger Causality Test Results for the Null Hypothesis that the Change in Aggregate Commodity Index Trader (CIT) Net Position Does Not Cause Returns, January 2004 through September 2009

$$
R_{t, k}=\alpha_{t}+\sum_{i=1}^{m} \gamma_{i, k} R_{t-i, k}+\sum_{j=0}^{n} \beta_{j, k} X_{t-j, k}+\varepsilon_{t, k} \text { for each market, } k, \text { and time, } t
$$

\begin{tabular}{lccccc}
\hline & & $\mathrm{p}$-value & Estimate & $\mathrm{p}$-value & One StdDev \\
Market, $\mathrm{k}$ & $\mathrm{m}, \mathrm{n}$ & $\beta_{j}=0, \forall j$ & $\sum \beta_{j}$ & $\sum \beta_{j}=0$ & Impact \\
\hline Cocoa & 1,1 & 0.841 & 0.00003 & & 0.011 \\
Coffee & 1,1 & 0.290 & 0.00013 & & 0.055 \\
Cotton & 1,1 & 0.766 & 0.00002 & & 0.015 \\
Sugar & 1,1 & 0.685 & 0.00001 & & 0.022 \\
Feeder Cattle & 1,1 & 0.816 & -0.00005 & & -0.006 \\
Lean Hogs & 2,1 & $\mathbf{0 . 0 0 1}$ & -0.00017 & & -0.130 \\
Live Cattle & 1,2 & $\mathbf{0 . 0 3 7}$ & -0.00004 & 0.479 & -0.027 \\
Corn & 1,1 & 0.127 & -0.00003 & & -0.080 \\
Soybeans & 1,1 & 0.154 & 0.00007 & & 0.070 \\
Soybean Oil & 1,1 & 0.053 & -0.00013 & & -0.095 \\
Wheat CBOT & 1,1 & $\mathbf{0 . 0 2 9}$ & -0.00009 & & -0.126 \\
Wheat KCBOT & 1,1 & 0.429 & -0.00011 & & -0.042 \\
\hline Notes $R$ is near & 1,16 & & \\
\hline
\end{tabular}

Notes: $R$ is nearby return and $X$ is change in aggregate CIT positions. The models for each individual market using OLS. The number of observations per commodity is 1,447 . Bold values are statistically significant at the $5 \%$ level. 
Table A2. OLS Granger Causality Test Results for the Null Hypothesis that the Change in Aggregate Commodity Index Trader (CIT) Net Position Does Not Cause Implied Volatility, January 2004 through September 2009

$$
V_{t, k}=\alpha_{t}+\sum_{i=1}^{m} \gamma_{i, k} V_{t-i, k}+\sum_{j=0}^{n} \beta_{j, k} X_{t-j, k}+D u m+\varepsilon_{t, k} \text { for each market, } k, \text { and time, } t
$$

\begin{tabular}{lccccc}
\hline & & $\begin{array}{c}\mathrm{p} \text {-value } \\
\beta_{j}=0, \forall j\end{array}$ & $\begin{array}{c}\text { Estimate } \\
\sum \beta_{j}\end{array}$ & $\begin{array}{c}\mathrm{p} \text {-value } \\
\sum \beta_{j}=0\end{array}$ & $\begin{array}{c}\text { One StdDev } \\
\text { Market, } \mathrm{k}\end{array}$ \\
\hline Cocoa & $5, \mathrm{n}$ & 0.681 & 0.00005 & & 0.020 \\
Coffee & 2,1 & 0.805 & -0.00003 & & -0.012 \\
Cotton & 5,1 & 0.148 & 0.00018 & 0.108 \\
Sugar & 4,1 & 0.954 & 0.00000 & 0.003 \\
Feeder Cattle & 5,1 & 0.154 & 0.00141 & 0.154 \\
Lean Hogs & 2,1 & 0.493 & -0.00017 & -0.126 \\
Live Cattle & 4,1 & 0.080 & -0.00010 & -0.068 \\
Corn & 1,1 & $\mathbf{0 . 0 2 9}$ & -0.00004 & -0.096 \\
Soybeans & 1,1 & 0.443 & 0.00003 & 0.028 \\
Soybean Oil & 3,1 & 0.655 & -0.00003 & & -0.020 \\
Wheat CBOT & 3,1 & 0.977 & 0.00000 & & -0.001 \\
Wheat KCBOT & 4,1 & 0.918 & 0.00001 & & 0.005 \\
\hline
\end{tabular}

Notes: $V$ is nearby implied volatility and $X$ is change in aggregate CIT positions. The models for each individual market using OLS. The number of observations per commodity is 1,447. Bold values are statistically significant at the $5 \%$ level. 
Table A3. OLS Granger Causality Test Results for the Null Hypothesis that the Change in Returns Does Not Cause the Change in Aggregate Commodity Index Trader (CIT) Net Position, January 2004 through September 2009

$$
X_{t, k}=\alpha_{t}+\sum_{i=1}^{m} \gamma_{i, k} R_{t-i, k}+\sum_{j=0}^{n} \beta_{j, k} X_{t-j, k}+\varepsilon_{t, k} \text { for each market, } k \text {, and time, } t
$$

\begin{tabular}{|c|c|c|c|c|c|}
\hline Market, $\mathrm{k}$ & $\mathrm{m}, \mathrm{n}$ & $\begin{array}{c}\text { p-value } \\
\gamma_{i}=0, \forall i\end{array}$ & $\begin{array}{l}\text { Estimate } \\
\sum \gamma_{i}\end{array}$ & $\begin{array}{l}\text { p-value } \\
\sum \gamma_{j}=0\end{array}$ & $\begin{array}{c}\text { One StdDev } \\
\text { Impact }\end{array}$ \\
\hline Cocoa & 5,2 & 0.045 & 21.97 & 0.036 & 45 \\
\hline Coffee & 1,2 & 0.026 & 12.49 & & 25 \\
\hline Cotton & 1,4 & 0.018 & 19.59 & & 37 \\
\hline Sugar & 1,2 & 0.110 & 46.08 & & 94 \\
\hline Feeder Cattle & 1,2 & 0.242 & 3.49 & & 3 \\
\hline Lean Hogs & 1,3 & 0.189 & 17.24 & & 25 \\
\hline Live Cattle & 1,3 & 0.007 & 49.79 & & 50 \\
\hline Corn & 1,3 & 0.000 & 160.00 & & 322 \\
\hline Soybeans & 2,2 & 0.000 & 154.02 & & 288 \\
\hline Soybean Oil & 1,3 & 0.019 & 24.09 & & 45 \\
\hline Wheat CBOT & 1,3 & 0.000 & 68.84 & & 152 \\
\hline Wheat KCBOT & 1,1 & 0.003 & 14.79 & & 29 \\
\hline
\end{tabular}

Notes: $R$ is nearby return and $X$ is change in aggregate CIT positions. The models for each individual market using OLS. The number of observations per commodity is 1,447 . Bold values are statistically significant at the $5 \%$ level. 
Table A4. OLS Granger Causality Test Results for the Null Hypothesis that Implied Volatility Does Not Cause the Change in Aggregate Commodity Index Trader (CIT) Net Position, January 2004 through September 2009

$$
X_{t, k}=\alpha_{t}+\sum_{i=1}^{m} \gamma_{i, k} V_{t-i, k}+\sum_{j=0}^{n} \beta_{j, k} X_{t-j, k}+D u m+\varepsilon_{t, k} \text { for each market, } k \text {, and time, } t
$$

\begin{tabular}{lccccc}
\hline & & $\begin{array}{c}\mathrm{p} \text {-value } \\
\gamma_{i}=0, \forall i\end{array}$ & $\begin{array}{c}\text { Estimate } \\
\sum \gamma_{i}\end{array}$ & $\begin{array}{c}\mathrm{p} \text {-value } \\
\sum \gamma_{j}=0\end{array}$ & One StdDev \\
Market, $\mathrm{k}$ & $\mathrm{m}, \mathrm{n}$ & & & & \\
\hline Cocoa & 5,2 & $\mathbf{0 . 0 0 0}$ & -2.57 & $\mathbf{0 . 0 3 5}$ & -21 \\
Coffee & 3,3 & 0.539 & -1.68 & 0.346 & -11 \\
Cotton & 1,4 & $\mathbf{0 . 0 0 0}$ & -7.55 & & -60 \\
Sugar & 1,2 & $\mathbf{0 . 0 0 1}$ & -26.55 & & -202 \\
Feeder Cattle & 1,2 & 0.530 & -0.36 & & -2 \\
Lean Hogs & 1,2 & 0.462 & -1.09 & & -18 \\
Live Cattle & 1,3 & $\mathbf{0 . 0 0 3}$ & -12.84 & & -57 \\
Corn & 5,3 & $\mathbf{0 . 0 2 1}$ & -20.55 & $\mathbf{0 . 0 0 9}$ & -178 \\
Soybeans & 1,1 & $\mathbf{0 . 0 0 6}$ & -9.82 & & -79 \\
Soybean Oil & 1,3 & $\mathbf{0 . 0 3 0}$ & -7.26 & & -43 \\
Wheat CBOT & 2,1 & $\mathbf{0 . 0 0 0}$ & -14.32 & $\mathbf{0 . 0 0 1}$ & -129 \\
Wheat KCBOT & 1,1 & 0.758 & -0.39 & & -3 \\
\hline
\end{tabular}

Notes: $V$ is nearby implied volatility and $X$ is change in aggregate CIT positions. The models for each individual market using OLS. The number of observations per commodity is 1,447. Bold values are statistically significant at the $5 \%$ level. 